\title{
Multiple Roles of T7 RNA Polymerase and T7 Lysozyme During Bacteriophage T7 Infection
}

\section{Xing Zhang and F. William Studier*}

Biology Department Brookhaven National Laboratory, Upton, NY 11973-5000, USA
T7 RNA polymerase selectively transcribes T7 genes during infection but is also involved in DNA replication, maturation and packaging. T7 lysozyme is an amidase that cuts a bond in the peptidoglycan layer of the cell wall, but it also binds T7 RNA polymerase and inhibits transcription, and it stimulates replication and packaging of T7 DNA. To better understand the roles of these two proteins during T7 infection, mutants of each were constructed or selected and their biochemical and physiological behavior analyzed. The amidase activity of lysozyme is needed for abrupt lysis and release of phage particles but appears to have no role in replication and packaging. The interaction between polymerase and lysozyme stimulates both replication and packaging. Polymerase mutants that gain the ability to grow normally in the absence of an interaction with lysozyme still fail to shut down late transcription and, remarkably, have become hypersensitive to inhibition when lysozyme is able to bind. These lysozyme-hypersensitive polymerases behave without lysozyme similarly to wild-type polymerase with lysozyme: both remain longer at the promoter before establishing a lysozyme-resistant elongation complex and both increase the length of pausing when elongation complexes encounter an eight-base recognition sequence involved in DNA packaging. Replication origins contain T7 promoters, but the role of T7 RNA polymerase in initiating replication is not understood well enough to more than speculate how the lysozyme-polymerase interaction stimulates replication. Maturation and packaging is apparently initiated through interaction between prohead-terminase complexes and transcription elongation complexes paused at the sequence TATCTGT(T/A), well conserved at the right-end of the concatemer junction of T7-like phages. A model that is consistent with the structure of an elongation complex and a large body of mutational and biochemical data is proposed to explain sequence-specific pausing and potential termination at the consensus recognition sequence $(\mathrm{C} / \mathrm{T}) \mathrm{ATCTGT}(\mathrm{T} / \mathrm{A})$.

(C) 2004 Elsevier Ltd. All rights reserved.

Keywords: T7 RNA polymerase; T7 lysozyme; DNA replication; DNA packaging; transcriptional pausing and termination

\section{Introduction}

Bacteriophage T7 specifies a single-subunit RNA polymerase of 883 amino acid residues that is

Present address: $X$. Zhang, Department of Biochemistry, Emory University, Atlanta, GA 30322, USA.

Abbreviations used: LH, lysozyme hypersensitive; LR, lysozyme resistant; SLH, suppressor of lysozyme hypersensitivity.

E-mail address of the corresponding author: studier@bnl.gov highly selective for promoters found in its own DNA but not in host DNA. ${ }^{1,2}$ By making T7 RNA polymerase early in infection and inactivating the host RNA polymerase, T7 efficiently directs all gene expression in the cell to its own DNA.

T7 RNA polymerase appears to have roles in replication and packaging of T7 DNA as well as in gene expression. ${ }^{2,3}$ All $\mathrm{T} 7$ replication origins used in vivo contain a promoter for T7 RNA polymerase, ${ }^{2,4}$ T7 RNA polymerase is required for proper initiation of replication in vitro, ${ }^{5}$ and $\mathrm{T} 7$ RNA polymerase synthesizes primers in vivo for leading-strand replication in the absence, and 
perhaps also in the presence, of the T7 primase. ${ }^{6}$ However, an attempt to isolate polymerase mutants defective in replication but not transcription was unsuccessful. ${ }^{3}$

Replication of T7 DNA proceeds through concatemers, that is, tandem repeats of mature DNA joined through a $160 \mathrm{bp}$ sequence that becomes the terminal repetition of mature T7 DNA in the maturation and packaging process. ${ }^{2,7}$ Packaging also requires a T7 promoter, $^{8}$ and promoter specificity determines the DNA packaging specificity of T3 and T7 phage in in vitro packaging experiments. ${ }^{9}$ Direct evidence for an essential involvement of T7 RNA polymerase in DNA packaging comes from the isolation of mutants of T7 RNA polymerase that are unable to produce the mature ends from concatemers or package DNA into proheads ${ }^{3}$ (J. J. Dunn \& F.W.S., unpublished results).

T7 lysozyme was identified and named for its activity in a lysozyme assay ${ }^{10}$ but was subsequently found to cut an amide bond in the peptidoglycan layer rather than the glycosidic bond cut by the classical egg-white or T4 lysozymes. ${ }^{11}$ Isolation of a $\mathrm{T} 7$ amber mutant deficient in lysozyme activity revealed other unusual features: ${ }^{12,13}$ the lysozyme gene (3.5) lies among and is expressed along with replication genes rather than late genes, and lack of T7 lysozyme reduces both replication and burst size while delaying but not preventing lysis, as measured by decrease in turbidity. Lysozyme is also required for shut-off of late transcription. ${ }^{14}$ The molecular basis for these unusual properties began to be understood when it was found that T7 lysozyme binds to T7 RNA polymerase and inhibits transcription. ${ }^{15,16}$ Binding to T7 RNA polymerase also inhibits the amidase activity of T7 lysozyme. ${ }^{17}$

Biochemical analysis and the three-dimensional (3D) structure revealed the 150 amino acid residue T7 lysozyme protein to be a single-domain protein with the amidase active site in a cleft that contains a zinc atom essential for activity. ${ }^{17}$ Mutational analysis indicated that the polymerase-binding surface lies on the outer surface of one side of the cleft, ${ }^{17}$ which was confirmed by the $3 \mathrm{D}$ structure of the complex between T7 lysozyme and T7 RNA polymerase. ${ }^{18}$ Also available are 3D structures for T7 RNA polymerase by itself, ${ }^{19}$ in a complex with a promoter, $^{20}$ or in transcription initiation ${ }^{21}$ or elongation complexes, ${ }^{22,23}$ which provide a framework for the interpretation of biochemical experiments. To better understand the functions of T7 RNA polymerase, T7 lysozyme and the interaction between them, we determined the amino acid changes caused by previous and newly obtained mutations in these two proteins, analyzed their effects on the infective process and in biochemical assays, and attempted to understand these effects in terms of the 3D structures.

\section{Results}

Previous work identified and characterized different types of polymerase and lysozyme mutations, ${ }^{3,15,17}$ and new types of mutations affecting these proteins were constructed or selected in the work reported here. To aid in following the presentation, the types, origins, selection and properties of the polymerase and lysozyme mutations relevant to this work are summarized in Table 1, the names, amino acid changes and some properties of polymerase mutations are listed in Table 3, and properties of different types and combinations of lysozyme and polymerase mutations are summarized in Table 4. Here, the term polymerase refers to T7 RNA polymerase and the term lysozyme refers to T7 lysozyme unless otherwise specified.

\section{T7 lysozyme mutants defective in amidase activity, polymerase binding or both}

Gene 3.5 amber mutants, such as Lys13a at Gln $34,{ }^{2}$ are generally rather leaky, forming small to medium-sized plaques on BL21 with about $50 \%$

Table 1. Mutations in T7 lysozyme and T7 RNA polymerase

\begin{tabular}{|c|c|c|c|c|c|}
\hline Gene & Mutation & Type & Origin & Reference & Description or isolation \\
\hline Lysozyme & $\Delta 3.5$ & Total defective & Clone & This work & Deletion of all but first five codons \\
\hline Lysozyme & sup & Not bind pol & Phage & 3,17 & Suppressors of LH polymerases \\
\hline Lysozyme & AK6 & Not bind pol & Clone & 17 & Deletion joins Ala1 to Lys6 \\
\hline Lysozyme & AFK136 & No amidase & Clone & This work & Deletion joins Ala129 to Lys136 \\
\hline Polymerase & 4107 & Total deletion & Phage & 56 & Deletion of entire polymerase \\
\hline Polymerase & X & Lysozyme hypersensitive & Clone & 3 & $\begin{array}{l}\text { Unable to support growth of } 4107 \text {, supports growth of } \\
4107, \text { AK } 6\end{array}$ \\
\hline Polymerase & BG & Lysozyme hypersensitive & Phage & This work & $\mathrm{BiG}$; large-plaque derivatives of AK6 \\
\hline Polymerase & SNB & Lysozyme hypersensitive & Phage & This work & $\begin{array}{l}\text { Suppressor of not binding; large-plaque derivatives of } \\
\text { SLH1 }\end{array}$ \\
\hline Polymerase & $\mathrm{OL}$ & Lysozyme resistant & Phage & $\begin{array}{l}\text { This work, } \\
15\end{array}$ & $\begin{array}{l}\text { Plaques from plating wild-type on host that supplies } \\
\text { an inhibitory excess of lysozyme }\end{array}$ \\
\hline Polymerase & SLH & Lysozyme resistant & Phage & This work & $\begin{array}{l}\text { Suppressor of LH; plaques from plating LH,AK6 on } \\
\text { host supplying inhibitory excess of lysozyme }\end{array}$ \\
\hline
\end{tabular}


efficiency. This plaque formation could be due to a small amount of active protein produced by readthrough of the amber codon, or it could indicate that lysozyme is not absolutely essential for phage growth. To eliminate any possibility of residual lysozyme activity, the deletion mutant $\Delta 3.5$, which eliminates the lysozyme coding sequence from amino acid residue 6 to the end of the protein, was constructed. A complementing plasmid that supplies a relatively low level of lysozyme is needed to propagate $\Delta 3.5$, since high levels of lysozyme produced from a plasmid strongly inhibit T7 growth (Table 2). ${ }^{15}$ On a non-complementing host, $\Delta 3.5$ forms pinpoint-sized plaques with less than $20 \%$ efficiency, indicating that at least some of the leakiness of lysozyme amber mutants was due to readthrough.

To analyze the effects of each of the activities of lysozyme independently, two small deletions were used. Mutant AK6 joins Ala1 to Lys6 of wild-type lysozyme, appears unable to bind to or inhibit T7 RNA polymerase, and retains full amidase activity. ${ }^{17}$ AK6 forms small plaques with normal plating efficiency. Mutant AFK136 joins Ala129 to Lys136 through a Phe residue. It has no detectable amidase activity, presumably because it lacks Cys130, which normally coordinates the $\mathrm{Zn}^{2+}$ that is essential for amidase activity. ${ }^{17}$ The AFK136 mutant protein is somewhat less soluble than wild-type lysozyme when expressed from a clone but retains its ability to bind RNA polymerase in a gel-shift assay ${ }^{16}$ (data not shown) and to inhibit T7 growth when overexpressed from a plasmid (Table 2), indicating that it retains the ability to inhibit T7 RNA polymerase in vivo. AFK136 forms only pinpoint plaques at low efficiency but can be fully complemented when the host contains a plasmid that expresses the lysis genes $\mathrm{R}$ and $\mathrm{Rz}$ of phage $\lambda$, indicating that its main defect is in lysis.

Table 2. Plaque formation by wild-type T7 and mutant bacteriophages on BL21 carrying plasmids that express different levels of T7 lysozyme

\begin{tabular}{lccccc}
\hline Plasmid & Insert & Wild & $\Delta 3.5$ & AK6 & BG1,AK6 \\
\hline None & & +++ & 0 & + & +++ \\
pAR4503 & 3.5 & +++ & ++ & ++ & + \\
pAR4521 & $\phi 2.5-3.5$ & +++ & ++ & +++ & \pm \\
pAR4525 & $\phi 10-3.5$ & ++ & + & ++ & 0 \\
pAR4509 & tet-3.5 & + & \pm & \pm & 0 \\
pAR4532 & $\phi 10-3.5-\phi 10$ & \pm & \pm & \pm & 0 \\
pAR4591 & $\phi 10-3.5-\phi 3.8-$ & \pm & 0 & & 0 \\
AFK136 & T10-AFK136- & \pm & 0 & & 0 \\
& $\phi 3.8-T \phi$ & & & & \\
\hline
\end{tabular}

The plasmids are described in Materials and Methods and are listed in order of increasing lysozyme level. The T7 mutations are described in Table 1. The pAR4591 and AFK136 plasmids were in BL21(DE3) and the latter plasmid carried the AFK136 mutation, which inactivates amidase activity.,+++++ and + indicate large, medium and small plaques with normal plating efficiency; \pm indicates tiny plaques with decreased plating efficiency; and 0 indicates no plaques were observed.

\section{Amidase activity is needed to release infective phage particles}

Lysis (as indicated by decrease in turbidity) and release of infective phage particles were measured during a single cycle of growth of wild-type T7 and the mutants $\Delta 3.5$, AK6 and AFK136. Relative to wild-type, lysis by AK6 (which supplies amidase activity) was delayed but equivalently abrupt, whereas lysis by $\Delta 3.5$ and AFK136 (which lack amidase activity) was delayed and more gradual (Figure 1A). $\Delta 3.5$ released very few infective phage particles, AK6 released about a third as many as wild-type (coincident with lysis), and AFK136 released infective particles only gradually, eventually reaching about half as many as wildtype (Figure 1B). However, addition of T7 lysozyme before the beginning of lysis enabled more abrupt (though still delayed) lysis and release of

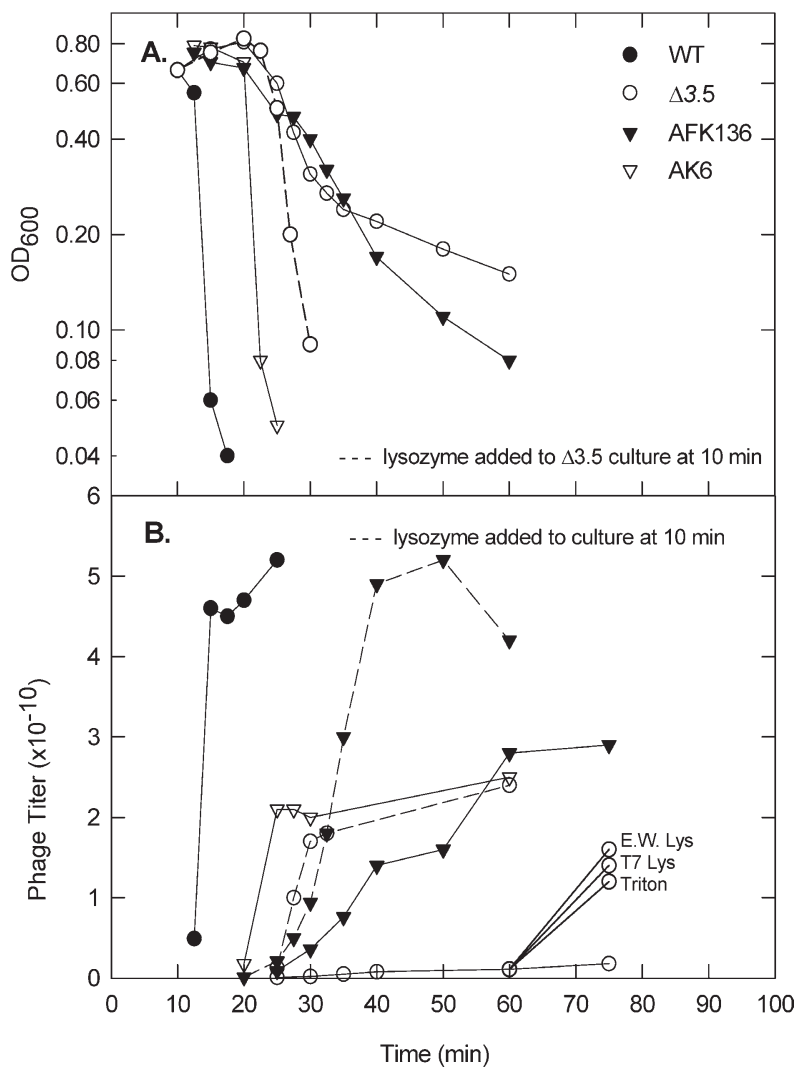

Figure 1. Lysis and phage release after infection by wild-type T7 or lysozyme mutants. BL21 cells grown in M9TB medium at $37^{\circ} \mathrm{C}$ to $A_{600 \mathrm{~nm}}$ of 0.6 were infected by T7 wild-type $(\bullet), \Delta 3.5(\bigcirc)$, AFK136 $(\boldsymbol{\nabla})$ or AK6( $\nabla)$ at a multiplicity of about 5 . At different times after infection, samples were taken for (A) reading $A_{600 \mathrm{~nm}}$ or (B) one minute centrifugation in a benchtop microfuge and titering of the supernatant on an appropriate host. The points connected by broken lines were from a portion of the culture to which T7 lysozyme $(20 \mu \mathrm{g} / \mathrm{ml})$ was added ten minutes after infection. Also shown are titers of samples to which T7 lysozyme $(20 \mu \mathrm{g} / \mathrm{ml})$, egg-white lysozyme $(100 \mu \mathrm{g} / \mathrm{ml})$ or $0.1 \%$ Triton X-100 were added 60 minutes after infection, followed at 75 minutes by centrifugation and titering. 
infectious phage particles from AFK136 and $\Delta 3.5$. AFK136 produced wild-type levels of phage particles, whereas $\Delta 3.5$ produced about a third of wild-type levels, comparable to AK6, which also cannot form lysozyme-polymerase complexes but supplies internal amidase activity (Figure 1B).

Most phage particles in lysates of the amidasedeficient $\Delta 3.5$ and AFK136 were in rapidly sedimenting material, from which they could be released not only by T7 lysozyme but also by eggwhite lysozyme or the detergent Triton X-100 (Figure 1B). The $\Delta 3.5$ phages released by added detergent had the same plating behavior as $\Delta 3.5$ that had been grown on a complementing host, eliminating the possibility that lysozyme protein may somehow be required to make phage particles infectious, either by acting on the phage particle or by participating in the entry process. The loss of turbidity late in infection by mutants that cannot make lysozyme may be due to the action of the T7 holin, which would allow much of the cell contents to leak out but leave the phage particles trapped inside cell ghosts because the peptidoglycan layer remains largely intact. ${ }^{24}$ The ability of the detergent Triton X-100 to release the phage particles in the absence of lysozyme suggests that more extensive disruption of the cell membrane than that caused by holin complexes may be sufficient to allow phage release, either itself or by providing access for other factors that can degrade the peptidoglycan layer.

\section{Lysozyme-polymerase complexes are required for normal replication and maturation of DNA, and for shutting off transcription}

Replication, as measured by incorporation of $\left[{ }^{3} \mathrm{H}\right]$ thymidine during infection, was delayed and reduced after infection with $\Delta 3.5$ (Figure 2A), as with a lysozyme amber mutant. ${ }^{13}$ An equivalent deficiency in replication was observed with AK6, which also lacks the ability to bind to T7 RNA polymerase but has normal amidase activity, whereas AFK136, which binds T7 RNA polymerase normally but lacks amidase activity, had a normal replication profile (Figure 2A). Thus, the polymerase-binding activity of T7 lysozyme is needed for normal replication and the amidase activity has no apparent effect on replication.

As expected, the mutants that cannot form lysozyme-polymerase complexes do not shut off T7 transcription during infection ${ }^{14}$ (shown for $\Delta 3.5$ in Figure 2B). The pattern of protein synthesis during infection (not shown) was normal for all three mutants, except for prolonged synthesis of some class II proteins during $\Delta 3.5$ and AK6 infection due to inability to shut-off transcription.

To learn more about the defect in replication, total DNA was isolated at different times after infection by wild-type, $\Delta 3.5$ and AK6, cut with a mixture of restriction endonucleases, and analyzed by electrophoresis in an agarose gel (Figure 3). Surprisingly, the mutant strains accumulated at least
A.
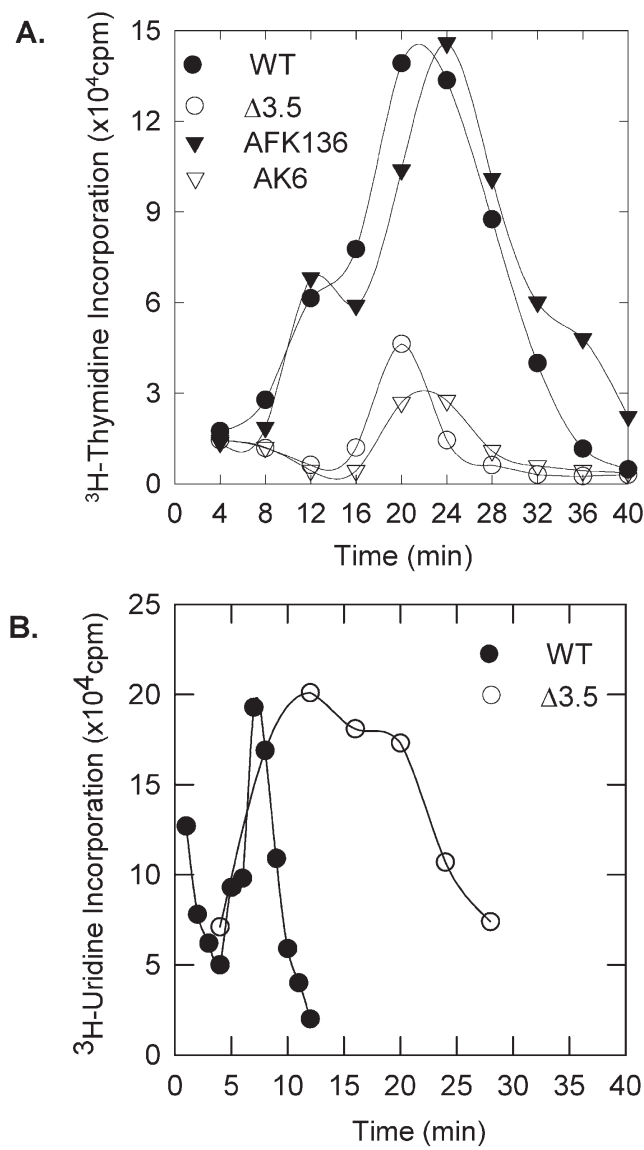

Figure 2. Replication and transcription during infection by wild-type T7 or lysozyme mutants. A culture of BL21 grown at $30{ }^{\circ} \mathrm{C}$ in M9 medium was infected with wild-type T7 $(\bullet), \Delta 3.5(\bigcirc)$, AFK136 $(\boldsymbol{\nabla})$ or AK6( $\nabla)$ at a multiplicity of about 10 . Acid-precipitable counts were measured from $100 \mu \mathrm{l}$ samples of culture labeled with (A) $10 \mu \mathrm{Ci} / \mathrm{ml}$ of $\left[{ }^{3} \mathrm{H}\right]$ thymidine for 30 seconds to measure rates of DNA synthesis, or (B) $10 \mu \mathrm{Ci} / \mathrm{ml}$ of $\left[5,6-{ }^{3} \mathrm{H}\right]$ uridine for one minute to measure rates of RNA synthesis, at times after infection as indicated.

half as much DNA as did wild-type, much more than would be expected from pulse-labeling experiments (Figure 2A). We attribute the difference in the two assays to a depression of $\left[{ }^{3} \mathrm{H}\right]$ thymidine incorporation caused by an imbalance between the release of nucleotides from host DNA and their incorporation into T7 DNA. Most of the nucleotides incorporated into T7 DNA come from degradation of host DNA, but synthesis of wild-type T7 DNA is so rapid that little release of acid-soluble label from host DNA can be detected during infection. ${ }^{12}$ Perhaps, when replication is delayed or reduced, release of precursors from host DNA increases internal pools, thereby decreasing the rate of incorporation of labeled thymidine more severely than the actual decrease in rate of DNA synthesis. Although pulse labeling with $\left[{ }^{3} \mathrm{H}\right]$ thymidine readily detects differences in replication caused by mutations in T7, it apparently is not a reliable quantitative measure of relative rates of replication or accumulation of $\mathrm{T} 7$ DNA. 
WT

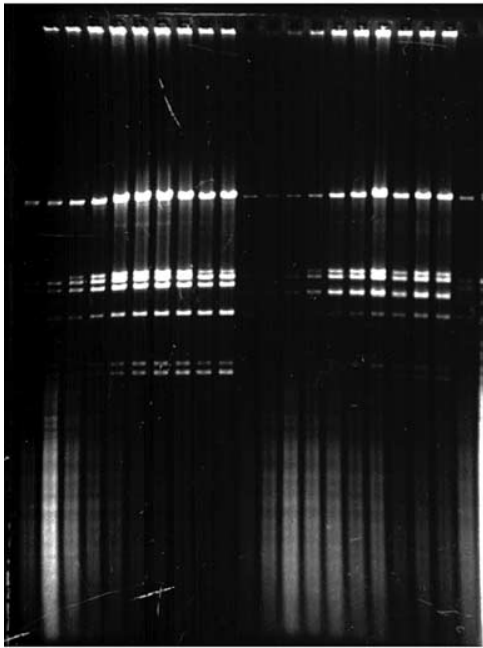

AK6
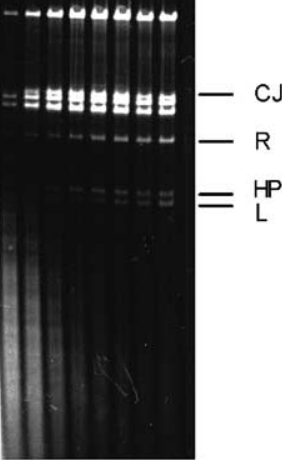

Figure 3. Total DNA synthesis during infection by wild-type T7 or lysozyme mutants. A culture of BL21 growing at $30^{\circ} \mathrm{C}$ in B25P medium was infected with wild-type T7, $\Delta 3.5$ or AK6 at a multiplicity of about 5 . Samples were collected every three minutes from nine to 36 minutes after infection and analyzed as described. ${ }^{3}$ Total DNA was digested with a mixture of BglI, BstNI, EcoRI, RNase A and RNase $\mathrm{T}_{1}$, and the patterns obtained by electrophoresis through a $0.8 \%$ agarose gel followed by staining with ethidium bromide are shown, with time of sample collection increasing from left to right. Positions of concatemer junction (CJ) and hairpin (HP) fragments from replicating DNA and left (L) and right (R) end fragments of mature T7 DNA are indicated.

The gel-electrophoretic analysis of total DNA (Figure 3 ) indicates that the $\Delta 3.5$ and AK6 mutants may have a somewhat delayed onset of replication, accumulate somewhat less T7 DNA, and degrade host DNA somewhat less rapidly than wild-type. Much more striking is the deficiency in the processing of concatemers into mature T7 DNA. T7 DNA replicates as concatemers, that is, tandem repeats of mature DNA joined through a $160 \mathrm{bp}$ sequence that forms a terminal repetition in mature $\mathrm{T} 7$ DNA. ${ }^{7}$ In the maturation and packaging process, a hairpin end is generated by rightward replication initiated just to the left of the terminal repetition sequence $^{25}$ (J. J. Dunn \& F.W.S., unpublished results). The concatemer-junction, hairpin, and left and right-end fragments are resolved and identified in the patterns of Figure 3.

In the wild-type pattern, the concatemer and hairpin bands decreased at late times after infection, as the concatemers were converted to mature left and right ends in the packaging process (Figure 3). However, in $\Delta 3.5$ and AK6, the concatemer-junction band decreased only slightly, if at all, and the hairpin, left and right-end fragments were severely reduced relative to the other fragments. (The hairpin and left-end fragments in the $\Delta 3.5$ pattern were distinctly visible in the original photograph but may not be visible in the reproduction.) Clearly, the polymerase-binding activity of T7 lysozyme stimulates the DNA maturation and packaging process.

In the DNA patterns shown in Figure 3, AK6 appeared to be not quite as defective as $\Delta 3.5$. This could be due to sampling differences, but it might indicate that the AK6 lysozyme retains a slight affinity for T7 RNA polymerase.

\section{Lysozyme is not required for initiation of DNA replication at secondary origins}

Replication of T7 DNA during a wild-type infection is initiated from a primary origin located at about $15 \%$ of genome length from the left end, but secondary origins are used when the primary origin is deleted and presumably later in infection as well. ${ }^{2,4,26}$ Rabkin \& Richardson ${ }^{4}$ stated that T7 lysozyme is essential for replication from secondary origins but not from the primary origin, which raised the interesting possibility that the replication defect caused by lysozyme deficiency may be related to an inability to use certain origins.

Locations of secondary origins have been determined by the ability of cloned fragments of T7 DNA to promote replication of plasmid DNA during T7 infection. ${ }^{2,4}$ Functional replication origins always include a promoter for T7 RNA polymerase but not all such promoters are part of replication origins. We tested cloned fragments carrying the primary origin and three known secondary origins, associated with the $\phi \mathrm{OR}, \phi 13$, and $\phi 6.5$ promoters, for their ability to promote plasmid replication during infection by wild-type T7 or $\Delta 3.5$. A cloned fragment containing the $\phi 10$ promoter, which is known not to serve as an origin, was used as a control. Contrary to the statement by Rabkin \& Richardson, the primary origin and all three secondary origins directed replication of plasmid DNA during $\Delta 3.5$ infection, although in all cases less well than during wild-type infection (consistent with a general replication deficiency) (Figure 4). We conclude that the replication defect caused by lack of lysozyme is unlikely to be due to an inability to use secondary replication origins.

\section{Polymerase mutations that suppress the DNA replication and maturation defect of a lysozyme mutant unable to bind polymerase}

AK6, which supplies amidase but is unable to bind polymerase, forms small plaques at normal efficiency, but big plaques arise at a low frequency and are readily isolated. These strains retain the AK6 mutation but have acquired a second mutation (named BG) that suppresses the AK6 growth deficiency. The burst sizes of these suppressed AK6 double mutants returned to the normal range (not shown), as did their ability to replicate and mature T7 DNA (Figures 5B and 6). However, they remained defective in shut-off of transcription during infection (Figure 5A), which demonstrates that the replication defect of 


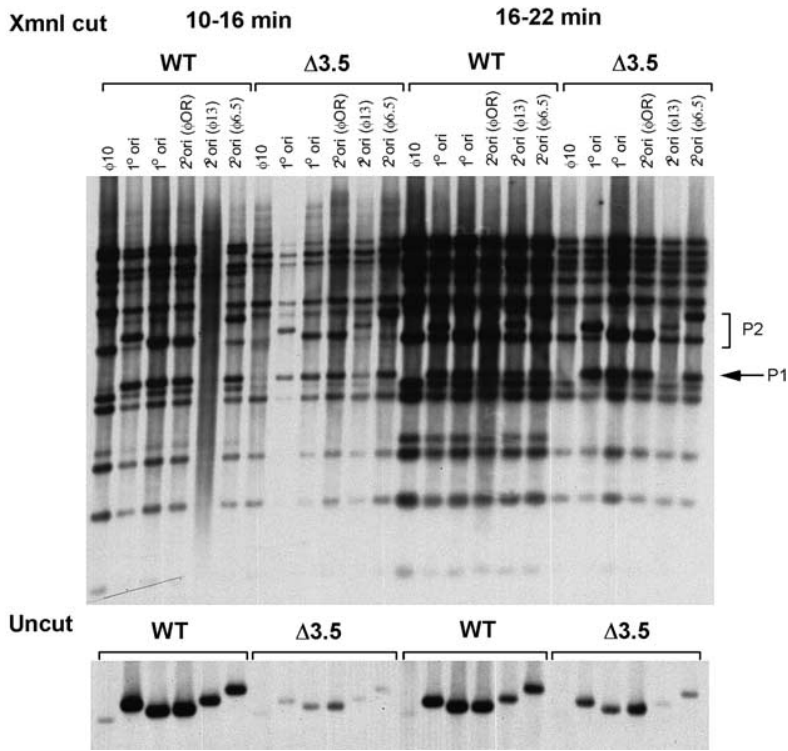

Figure 4. Utilization of cloned origins of replication during infection by wild-type T7 or $\Delta 3.5$. Cultures of HMS174 infected with wild-type T7 or $\Delta 3.5$ were assayed for $\mathrm{T} 7$ replication origin activity of different fragments of T7 DNA cloned in the BamHI site of pBR322, as described in Materials and Methods. Labeling was from 10 to 16 minutes or 16 to 22 minutes after infection, as indicated. The upper panel shows electrophoretic patterns of total DNA after cutting with XmnI and the lower panel shows uncut plasmid DNA from the same samples. The plasmids, in order from left to right in the Figure, were the control plasmid pET-1 ( $\phi 10$ promoter, $22,881-22,928$ of T7 DNA); two plasmids that carry the primary origin of replication (designated $1^{\circ}$ ori in the Figure), pAR689 $(\phi 1.1 \mathrm{~A}, \phi 1.1 \mathrm{~B}$ promoters, $5670-$ $6019)$ and pAR741 $(\phi 1.1 \mathrm{~A}, \phi 1.1 \mathrm{~B}$ promoters, 5818 6019); and three plasmids that carry secondary origins ( $2^{\circ}$ ori in the Figure), pAR857 ( $\phi \mathrm{OR}$ promoter, 39,110 $39,307)$, pAR665 ( $\phi 13$ promoter, 27,089-27,479) and pAR775 ( $\phi 6.5$ promoter, 18,519-19,178). The smaller, constant-length fragment from the plasmids is labeled P1 in the Figure; the larger, variable-length fragment that contains the cloned T7 DNA is labeled P2.

lysozyme mutants is not due to interference with replication by a continued high level of transcription by T7 RNA polymerase.

Wild-type lysozyme must somehow stimulate replication through its interaction with polymerase, and it seemed likely that the BG suppressor mutations were either in the lysozyme or polymerase gene. Indeed, the BG mutations in the analyses shown in Figures 5 and 6 were in polymerase, causing the amino acid changes A465T (BG1), H545Y (BG5), A702T (BG8) and R829H (BG6) (Table 3). (Mutations are referred to by wild-type amino acid, position, and mutant amino acid, using single-letter designations.) The BG mutations are widely distributed in the amino acid sequence and in the 3D structure of polymerase.

We were surprised to find that the BG1 mutation was the same as $\mathrm{X} 19$, one of a class of previously identified T7 RNA polymerase mutants that have an increased sensitivity to inhibition by lysozyme. ${ }^{3}$
Referred to as lysozyme hypersensitive (LH), these polymerase mutants do not support T7 growth but can be suppressed by lysozyme mutants that have a decreased ability to inhibit polymerase. $3,16,17$ In fact, the AK6 mutant, which appears not to bind or inhibit polymerase, was constructed because lysozyme mutations that allowed growth of LH polymerase mutants affected four of the first five residues of lysozyme. Thus, selection of BG polymerase mutants as suppressors of the AK6 mutation in lysozyme is the reciprocal of the selection of lysozyme mutants as suppressors of LH mutations in polymerase, and perhaps we should not have been surprised that at least some of the BG mutations would turn out to be LH polymerase mutants.

\section{Characterization of Iysozyme-hypersensitive (LH) mutants of T7 RNA polymerase}

To test what fraction of BG mutants were $\mathrm{LH}$ polymerase mutants, each of the BG,AK6 strains was plated on cells carrying plasmids that supplied various levels of wild-type T7 lysozyme (Table 2). Plasmids that produce low levels, such as pAR4503 and pAR4521, were hardly inhibitory to wild-type or AK6 but significantly reduced the plaque size of all BG,AK6 mutants, represented by BG1,AK6 in Table 2. Plasmid pAR4525 was only slightly inhibitory to wild-type and AK6 but completely prevented BG,AK6 mutants from forming plaques. Therefore, all of the BG mutant polymerases we isolated are indeed hypersensitive to inhibition by wild-type lysozyme.

Restoration of normal replication and phage yield by BG suppressor mutations could conceivably involve an ability of AK6 mutant lysozyme to interact with the BG or other LH mutant polymerases. However, this possibility was eliminated by making T7 double mutants combining BG (or other LH) polymerases with the $\Delta 3.5$ mutation, which completely eliminates the lysozyme protein and therefore any possibility of forming a lysozyme-polymerase complex. As expected, the pattern of transcription, replication, and DNA packaging of $\mathrm{BG}, \Delta 3.5$ mutants was similar to that of BG,AK6 mutants, and the LH mutants X4 $(\mathrm{A} 821 \mathrm{~T})$ and $\mathrm{X} 19 \quad(\mathrm{~A} 465 \mathrm{~T})^{3}$ behaved similarly (Figures 5C and D, and 6). The BG, $\Delta 3.5$ and $\mathrm{LH}, \Delta 3.5$ mutants were unable to form plaques on BL21 because lack of amidase activity did not allow proper lysis and phage release, but they could be isolated because they formed normal plaques when lytic activity was supplied from a plasmid, either as AK6 lysozyme or $\lambda$ lysis genes. LH mutants are unable to grow in the presence of normal amounts of wild-type lysozyme because premature shut-off of transcription by the lysozyme-polymerase interaction prevents significant expression of crucial late T7 genes. ${ }^{3}$

Altogether, $15 \mathrm{LH}$ mutations that were isolated by random mutagenesis and selection ${ }^{3}$ (X mutations in Table 3) and 11 BG suppressors of 
Transcription
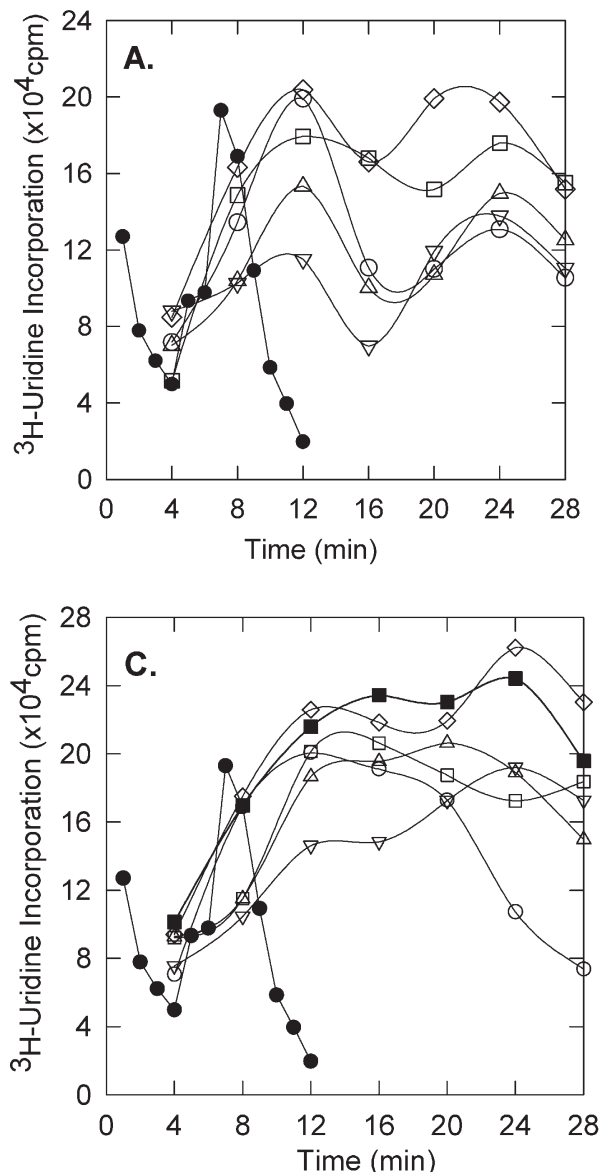

Replication
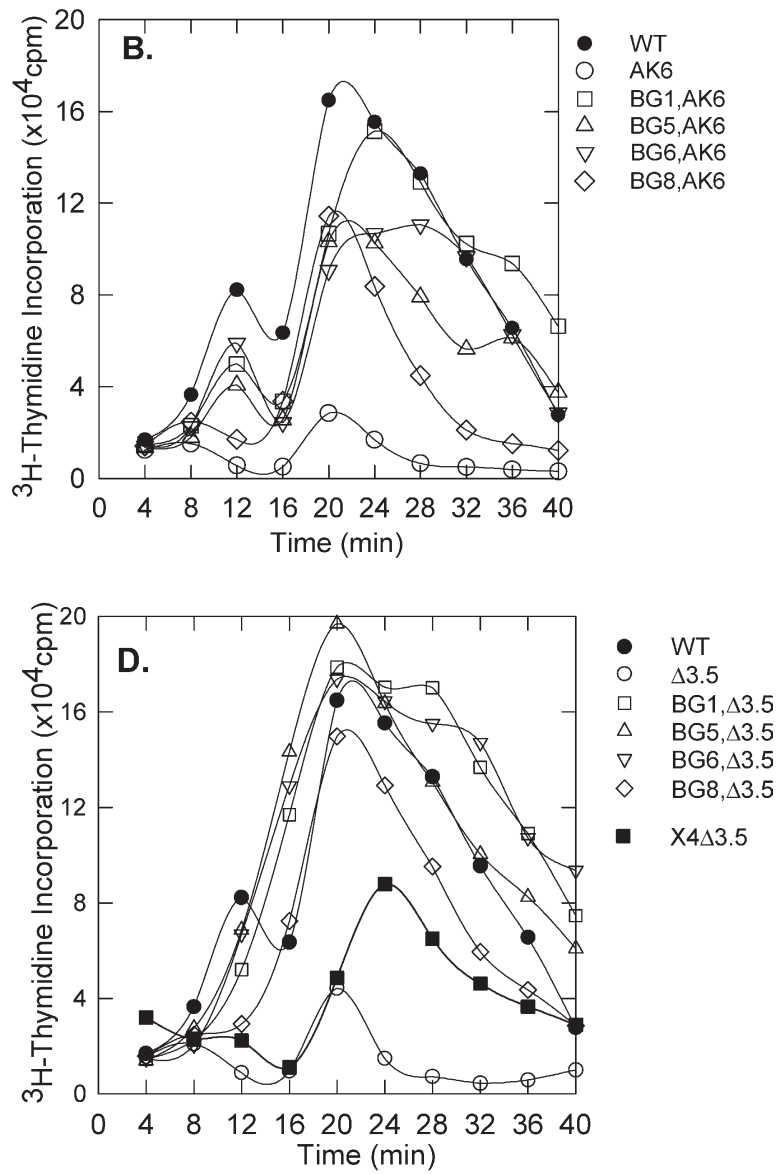

Figure 5. Transcription and replication during infection by BG,AK6 and BG, $\Delta 3.5$ double mutants. Experiments were performed as described in the legend to Figure 2. The upper panels show results from wild-type T7 $(\bullet)$; AK6 (O); BG1(A465T),AK6 $(\square)$; BG5(H545Y),AK6 $(\triangle)$; BG6(R829H),AK6 $(\nabla)$; and BG8(A702T),AK6 $(\diamond)$. The lower panels show results from wild-type T7 $(\bullet) ; \Delta 3.5(\mathrm{O}) ; \mathrm{BG} 1(\mathrm{~A} 465 \mathrm{~T}), \Delta 3.5(\square) ; \quad \mathrm{BG} 5(\mathrm{H} 545 \mathrm{Y}), \Delta 3.5(\Delta) ; \quad \mathrm{BG} 6(\mathrm{R} 829 \mathrm{H}), \Delta 3.5(\nabla)$; BG8(A702T) $\Delta 3.5(\diamond)$ and $X 4(\mathrm{~A} 821 \mathrm{~T}) \Delta 3.5(\mathbf{\square})$.

AK6 mutant lysozyme were located in the coding sequence for T7 RNA polymerase. These 26 mutations affected 18 different amino acid residues distributed across the C-terminal three-quarters of the amino acid sequence of the protein (Table 3). Four of the amino acid changes were found more than once (A465T, G469D, S547F and R829H), three of them being represented in both $X$ and $B G$ mutants.

\section{Polymerase mutants that tolerate increased levels of lysozyme}

Polymerase mutants with decreased sensitivity to lysozyme (the opposite of LH mutants) will be referred to generically as lysozyme-resistant (LR) mutants. LR mutants selected as T7 phage mutants that escaped growth inhibition by excess lysozyme supplied from a plasmid are referred to as OL mutants (overcomes lysozyme inhibition). ${ }^{15}$ The OL5 mutant had a delayed shut-off of transcription but appeared to replicate and package DNA well and form good plaques. However, it was noted that wild-type revertants would accumulate when OL mutants were grown in the absence of excess lysozyme, an indication that these mutants have some deficiency relative to wild-type. In addition to the seven original OL mutants, we isolated 32 more, numbered OL11-OL36 and OL41-OL46.

Genetic mapping of OL mutations is difficult because they have no easily selectable phenotype, but the sequence changes caused by OL2 (M549I) and OL5 (S856P) were identified because they affected restriction sites. ${ }^{15}$ To identify the amino acid changes in 32 additional OL mutations, mutant DNAs were first sequenced in regions near the two OL mutations of known position. DNAs for which no mutation was identified in this initial screen were then sequenced more broadly until a sequence change was identified in each mutant DNA. The 34 mutants analyzed contained 25 different mutations affecting 20 different amino acid residues distributed across the C-terminal half of the amino acid sequence (Table 3). Six of the amino acid changes were found more than once, and more than one 


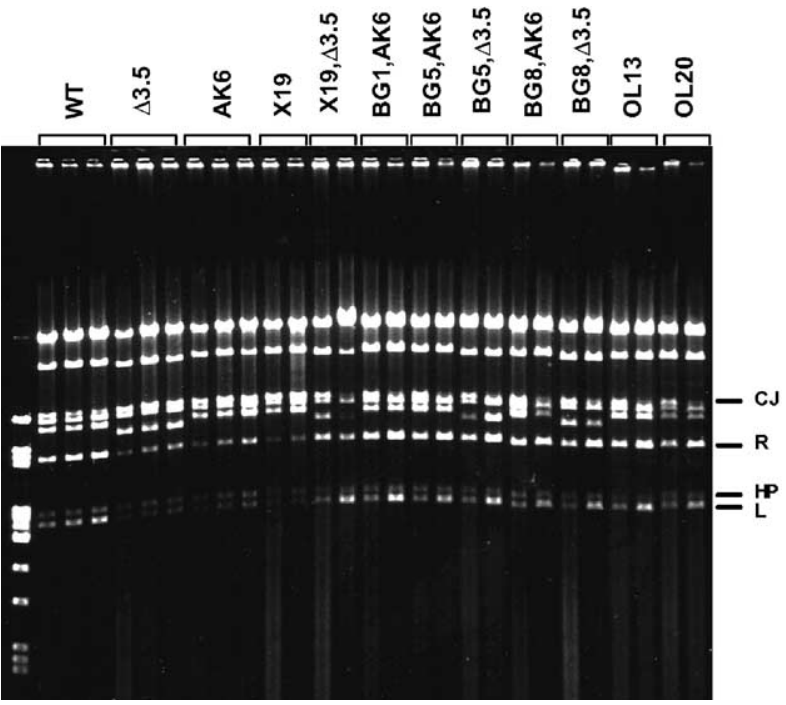

Figure 6. Total DNA synthesis during infection by wild-type $\mathrm{T} 7$ or different combinations of polymerase and lysozyme mutants. Experiments were performed as described in the legend to Figure 3 with samples collected 20 minutes and 28 minutes after infection, with an additional sample at 24 minutes for wild-type, $\Delta 3.5$ and AK6. X19 and BG1 have the same polymerase mutation (A465T), and the other polymerase mutations were BG5 (H545Y), BG8 (A702T), OL13 (A827E) and OL20 (G555A).

replacement for the wild-type amino acid was found at five positions.

\section{Effect of LH and LR mutations on formation of Iysozyme-polymerase complexes}

One possible way for polymerase to increase or decrease its sensitivity to inhibition by lysozyme would be to change its binding affinity. Indeed, the only LR mutant tested previously, OL5 (S856P), had a decreased affinity for lysozyme, as measured by ability of lysozyme to bind to polymerase that was linked to a column matrix. ${ }^{15}$ The wide distribution of LR and LH mutants in the amino acid sequence makes it unlikely that all of the amino acid residues affected by either type could make contacts with lysozyme, but affinity could perhaps be influenced in more subtle ways.

To analyze the ability of mutant polymerases to bind lysozyme, wild-type and several LH and LR mutant polymerases were partially purified from extracts of cells in which they had been expressed from a clone. The yield of protein was typically considerably lower for the mutants than for wildtype, mostly due to reduced solubility. These partially purified proteins were then tested for binding in a gel-shift electrophoresis assay. ${ }^{16}$

Results for representative mutant polymerases are shown in Figure 7, where the numbers give the approximate molar ratio of unlabeled polymerase to $\left.{ }^{35} \mathrm{~S}\right] \mathrm{methionine-labeled} \mathrm{lysozyme}$ at a lysozyme concentration of $0.6 \mu \mathrm{M}$. When a mutant polymerase can bind lysozyme with an affinity
Table 3. T7 RNA polymerase mutations

\begin{tabular}{|c|c|c|c|c|}
\hline Mutation & $\begin{array}{c}\text { Lysozyme } \\
\text { hypersensitive }\end{array}$ & $\begin{array}{l}\text { Lysozyme } \\
\text { resistant }\end{array}$ & Clone & $\begin{array}{l}\text { Bind } \\
\text { Lys }\end{array}$ \\
\hline $\mathrm{R} 231 \mathrm{H}$ & BG14 & & & \\
\hline G235D & X60 & & X60 & \\
\hline P361S & X126 & & X126 & \\
\hline G442R & X131 & & X131 & \\
\hline A465T & $\begin{array}{c}\text { X19, X82, X83, } \\
\text { BG1, SNB10 }\end{array}$ & & X19 & + \\
\hline G469D & X55, BG10 & & X55 & \\
\hline $\mathrm{R} 478 \mathrm{H}$ & $\begin{array}{l}\text { SNB3, SNB5, } \\
\text { SNB7, SNB8 }\end{array}$ & & & \\
\hline $\mathrm{R} 478 \mathrm{C}$ & SNB13 & & & \\
\hline P533L & X117 & & X117 & \\
\hline H545Y & BG5 & & 4629 & \\
\hline S547F & X76, X77, X119 & & X76 & \\
\hline M549I & & OL2, OL23 & 4631 & + \\
\hline G555A & & OL20 & 4632 & + \\
\hline $\mathrm{A} 702 \mathrm{~T}$ & BG8 & & 4630 & + \\
\hline A703T & & $\begin{array}{l}\text { OL14, OL21, } \\
\text { OL29, SLH20 }\end{array}$ & 4741 & + \\
\hline L705M & & OL7 & & \\
\hline L706P & & OL45 & & \\
\hline A708T & & OL30 & & \\
\hline A708V & & OL43 & & \\
\hline E709K & & OL41 & 4742 & $t^{a}$ \\
\hline $\mathrm{R} 720 \mathrm{H}$ & & OL18 & & \\
\hline R720S & & OL44 & & \\
\hline A724V & & OL36 & & \\
\hline A724S & & OL27 & & \\
\hline $\mathrm{H} 726 \mathrm{~N}$ & & OL24 & & \\
\hline V728L & & OL15 & & \\
\hline E738K & & OL46 & & \\
\hline E775G & & OL32 & 4743 & + \\
\hline S776P & BG9 & & 4745 & \\
\hline V783I & & OL34 & 4744 & + \\
\hline A821T & X4, SNB1, SNB2 & & $\mathrm{X} 4$ & + \\
\hline A $827 \mathrm{~V}$ & & OL3 & & \\
\hline A827E & & OL13, OL28 & 4732 & \\
\hline V828A & BG4 & & 4730 & \\
\hline $\mathrm{R} 829 \mathrm{H}$ & BG6, X191, X212 & & 4731 & \\
\hline T835A & & OL32, OL42 & 4733 & $+^{a}$ \\
\hline F849L & & OL4, OL11 & 4734 & + \\
\hline F849C & & OL16 & & \\
\hline Q852R & & $\begin{array}{l}\text { SLH1 }(+11 \\
\text { others) }\end{array}$ & 4735 & 0 \\
\hline Q852L & & SLH8 & & \\
\hline Q852P & & SLH11, SLH17 & & \\
\hline$\widetilde{Q} 852 \mathrm{H}$ & & SLH16, SLH18 & 4736 & 0 \\
\hline L853S & & SLH4 & 4737 & $0^{a}$ \\
\hline \multirow[t]{2}{*}{ S856P } & & OL5 & 1881 & 0 \\
\hline & & OL19 & 4738 & 0 \\
\hline P862L & & OL31 & 4739 & $0^{\mathrm{a}}$ \\
\hline P865Q & & OL17 & 4740 & 0 \\
\hline L870S & BG11 & & & \\
\hline F880L & BG3 & & 4729 & \\
\hline A881T & X56 & & X56 & \\
\hline A883V & BG13 & & & \\
\hline
\end{tabular}

The amino acid change for each mutation is given (wild-type, amino acid number, mutant) as are the isolation numbers of mutants containing the mutation, the designation of expressible clones of T7 RNA polymerase containing the mutation, and the results of tests of the mutant polymerase for ability to bind T7 lysozyme.

a Tested with crude extract only.

greater than some minimum value, essentially all of the labeled lysozyme shifts from the position of free lysozyme to that of the lysozyme-polymerase complex when the molar ratio of polymerase to lysozyme is greater than 1. This behavior is 


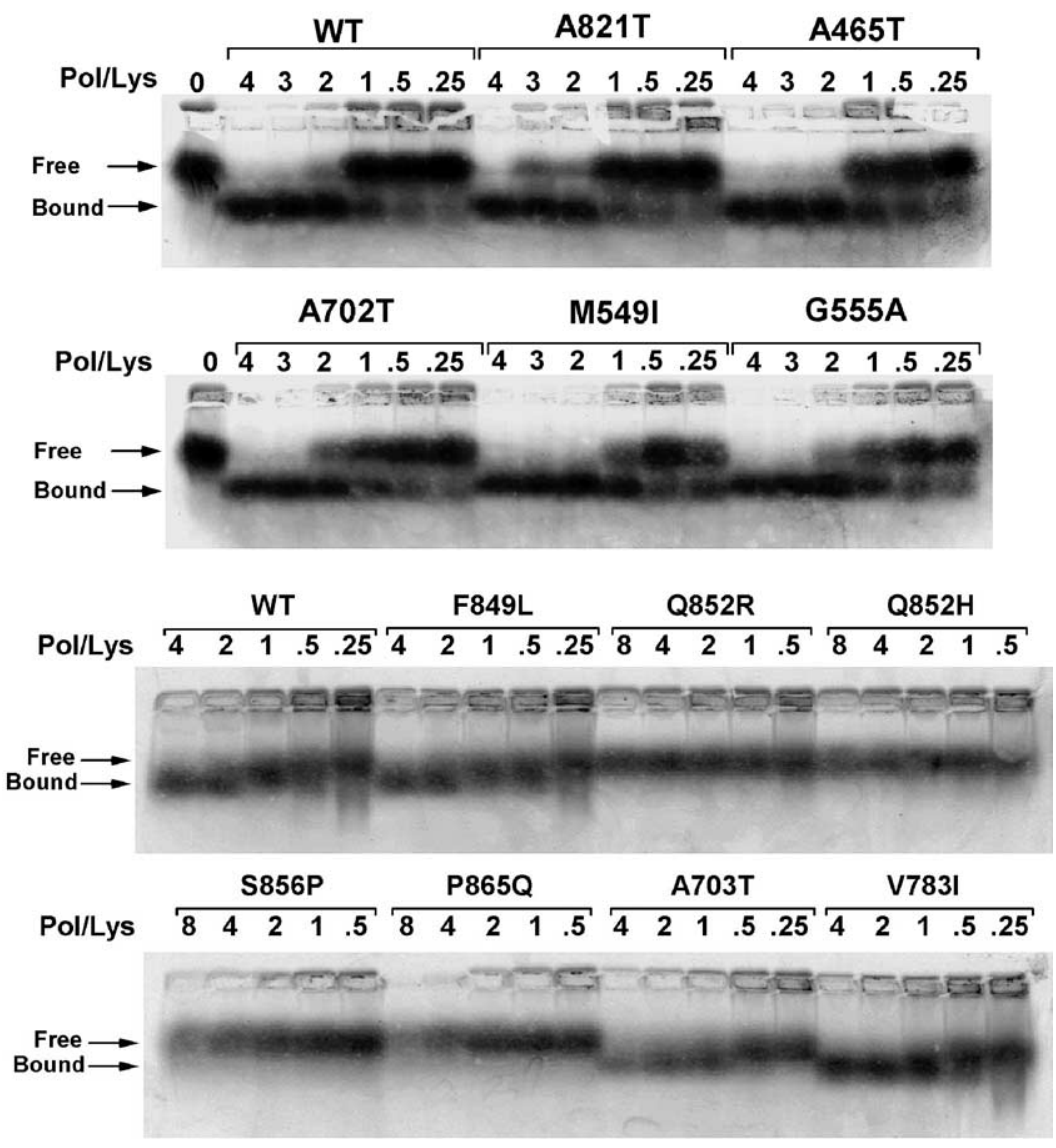

Figure 7. Ability of different polymerase mutants to form a complex with lysozyme. Partially purified wild-type or mutant polymerase $(2.4,1.8,1.2,0.6,0.3$ and $0.15 \mu \mathrm{M}$ from left to right in each set) was mixed with approximately $0.6 \mu \mathrm{M} \quad\left[{ }^{35} \mathrm{~S}\right]$ methionine-labeled lysozyme and incubated for ten minutes at room temperature in transcription buffer before electrophoresis through a $1 \%$ agarose gel in $20 \mathrm{mM}$ potassium phosphate (pH 7.7) as described. ${ }^{16}$ The first lane in each set contained no polymerase. Bands that represent free lysozyme or lysozyme bound to polymerase are indicated. Apparent discrepancies from 1:1 stoichiometry were probably due to the inaccuracy in estimating the concentration of labeled lysozyme and/or the mutant polymerases. The polymerase mutants were $\mathrm{X} 4$ (A821T), X19 (A465T), BG8 (A702T), OL2 (M549I), OL20 (G555A), OL11 (F849L), SLH1 (Q852R), SLH16 (Q852H), OL19 (S856P), OL17 (P865Q), OL14 (A703T) and OL34 (V783I).

apparent for LH mutant polymerases X4 (A821T), X19 (A465T) and BG8 (A702T) and for LR mutant polymerases OL2 (M549I), OL4 (F849L), OL14 (A703T), OL20 (G555A) and OL34 (V783I) (Figure 7), indicating that each of these polymerases is capable of binding lysozyme with an affinity greater than some level. On the other hand, OL5 (S856P) and OL17 (P865Q) show little if any label at the position of the lysozyme-polymerase complex even at polymerase to lysozyme ratios of $8: 1$, indicating that they have a reduced affinity for lysozyme. Although little label moved to the position of the complex, an evident smearing of the label at the position of free lysozyme at high polymerase to lysozyme ratios indicates that the OL5 and OL17 mutant polymerases may have some affinity for lysozyme.

A total of 11 LR mutants were tested in the gelshift assay and the results are summarized in Table 3. Eight LR mutants with amino acid changes located in the interval from amino acid residues 549 to 849 all seemed to bind lysozyme whereas three mutations located from amino acid residues 856 to 865 showed little if any binding in this assay. It appears that most LR mutant polymerases remain capable of binding lysozyme, and only those polymerases in which amino acid residues have been changed in a region bounded approximately by amino acid residues 850 and 869 are likely to have significantly reduced affinity for lysozyme. Although the gel-shift assay cannot make fine discriminations in affinity above a certain minimum, the effects of most LH or LR mutations on T7 growth are unlikely to be due simply to changes in affinity for lysozyme.

\section{Selection for polymerase mutants having reduced affinity for lysozyme}

Only a minor fraction of OL mutants appear to have a significantly reduced affinity for lysozyme, suggesting that the primary modes of accommodation to growth in excess lysozyme are due to other changes in the function of the polymerase. We reasoned that direct selection for polymerase mutants unable to bind lysozyme might be possible by plating LH mutant phages on a host that supplies excess lysozyme. Compensating for excess lysozyme should be more difficult in hypersensitive mutants and, since LH mutants grow normally in the absence of lysozyme, the most likely compensating mutations might be those that eliminate the ability to form a polymerase-lysozyme complex. Such mutations in polymerase would permit the phage to grow but those in lysozyme would not, because the host provides wild-type lysozyme. Therefore, we plated lysozyme-hypersensitive BG,AK6 double-mutant phages on HMS174/pAR1643, which supplies enough lysozyme to prevent plaque formation by wild-type T7. ${ }^{15}$

Five BG,AK6 double mutants were tested, BG1 
(A465T), BG3 (F880L), BG4 (V828A), BG5 (H545Y) and BG8 (A702T). In each case, plaques of about wild-type size were observed at a frequency of about $10^{-6}$. Three or four plaques derived from each original double-mutant phage were isolated (19 total), and they were named according to the BG mutant from which they derived plus a sequential suppressor of lysozyme hypersensitivity (SLH) number from BG1,SLH1 to BG8,SLH20. Sequencing showed that the original BG mutation was retained in each of these BG,SLH phages. Surprisingly, 17 of the $19 \mathrm{SLH}$ mutations isolated in this way affected glutamine 852,12 changing it to arginine and the others changing it to leucine, proline or histidine (Table 3). Another mutation changed the adjacent leucine 853 to serine. Gel-shift assays showed that mutations at both positions reduced the affinity for lysozyme to undetectable levels (Figure 7 and Table 3). The failure of the SLH mutant polymerases Q852R and $\mathrm{Q} 852 \mathrm{H}$ to bind lysozyme in the gel-shift assay was not due to denaturation of the polymerase during purification, since both were fully active in transcription assays (not shown). The purified OL mutant polymerases S856P and P865Q, which also have reduced affinity for lysozyme, were somewhat less active in transcription assays.

The remaining mutant obtained in this selection, BG8,SLH20, apparently compensated for the LH mutation BG8 (A702T) with an LR mutation (A703T) at the next amino acid. The amino acid change in SLH20 was the same as that in three independently isolated OL mutations, and this LR mutation apparently overcame the LH phenotype of the adjacent BG mutation in the double mutant.

\section{Selection for lysozyme-hypersensitivity mutations in polymerase mutants unable to bind lysozyme}

The SLH1, SLH16 and SLH4 mutations Q852R, Q852H and L853S, and the OL19 mutation P862L, all of which confer deficiency in binding to lysozyme, were transferred from the cloned polymerase into wild-type T7 by recombination and selection for ability to grow in the presence of excess lysozyme. Phages carrying the Q852R or $\mathrm{Q} 852 \mathrm{H}$ mutation alone (with no LH mutation) formed small plaques whether or not lysozyme was supplied from a clone, and the plaques were similar in size to those of AK6. This is the expected result if the only defect of these mutant polymerases is inability to bind lysozyme, since the wild-type lysozyme would contribute amidase activity but would be unable to stimulate DNA replication and maturation by binding polymerase (a situation equivalent to AK6, where the mutant lysozyme provides amidase activity but is unable to bind to wild-type polymerase). The L853S and P862L mutant phages gave plaques that were somewhat smaller than wild-type plaques but larger than those of the Q852R or Q852H mutant phages or AK6, suggesting that the L853S and
P862L polymerases may be not as defective in binding lysozyme.

If the SLH1 (Q852R) mutant polymerase is indeed equivalent to AK6 (in that the only significant defect is inability to form a lysozyme-polymerase complex), SLH1 should give rise to big plaques containing LH mutants in the same way that AK6 gave rise to BG mutants. Indeed, largeplaque mutants were obtained (referred to as SNB, suppressor of not binding lysozyme). Of eight SNB mutations sequenced, two corresponded to the previously identified LH mutation X4 (A821T) and one to X19 (A465T), four contained an R478H mutation, and one contained an R478C mutation (Table 3). Thus, the SLH1,SNB10 double mutant obtained as a large-plaque derivative of SLH1 was apparently identical with the BG1,SLH1 double mutant derivative of BG1 obtained by ability to grow on a host that supplied excess lysozyme. It appears that large-plaque derivatives of SLH1 (Q852R) are generally functionally equivalent to large-plaque derivatives of AK6: in each case, an LH mutation suppresses the replication and maturation defect of a mutant that is unable to form a lysozyme-polymerase complex.

\section{Effect of lysozyme on promoter binding and formation of short transcripts by LH and LR mutant polymerases}

The LH mutant polymerases X4 (A821T), X19 (A465T) and BG8 (A702T) and the LR mutant polymerases OL2 (M549I) and OL20 (G555A) were found in a gel-shift assay to bind to a DNA fragment containing the $\phi 10$ promoter indistinguishably from wild-type polymerase, in the presence or absence of lysozyme (data not shown). Thus, the biochemical and physiological differences among these polymerases are apparently not due to differences in the ability to bind the promoter.

Ability to form abortive transcripts and short runoff RNAs by initiation at the $\phi 10$ promoter was examined for the same polymerases (Figure 8). Four different nucleotide triphosphate mixtures allowed the synthesis of a $G$ ladder, six base or 15 base stalled products, and 24 base runoff RNAs. Transcription products from reactions containing no lysozyme or a $10: 1$ molar ratio of lysozyme to polymerase are shown in adjacent lanes of Figure 8 for each polymerase. In the absence of lysozyme, differences in transcription patterns by the different polymerases were relatively minor, although $\mathrm{X} 4$ seemed to be slightly less active than the other polymerases, particularly in the runoff reaction (all four NTPs). Lysozyme inhibited all three LH mutant polymerases much more strongly than wild-type, whereas the two LR mutants appeared as resistant or more resistant to inhibition than wild-type. The strong inhibition of abortive transcription suggests that lysozyme significantly depressed the rate of phosphodiester bond formation by the initiation complexes of the LH mutants. 
G $\quad$ GA

$\begin{array}{lllllllllll}\text { WT } & \text { X4 } & \text { X19 } & \text { BG8 OL2 OL20 WT X4 X19 } & \text { BG8 OL2 OL20 }\end{array}$

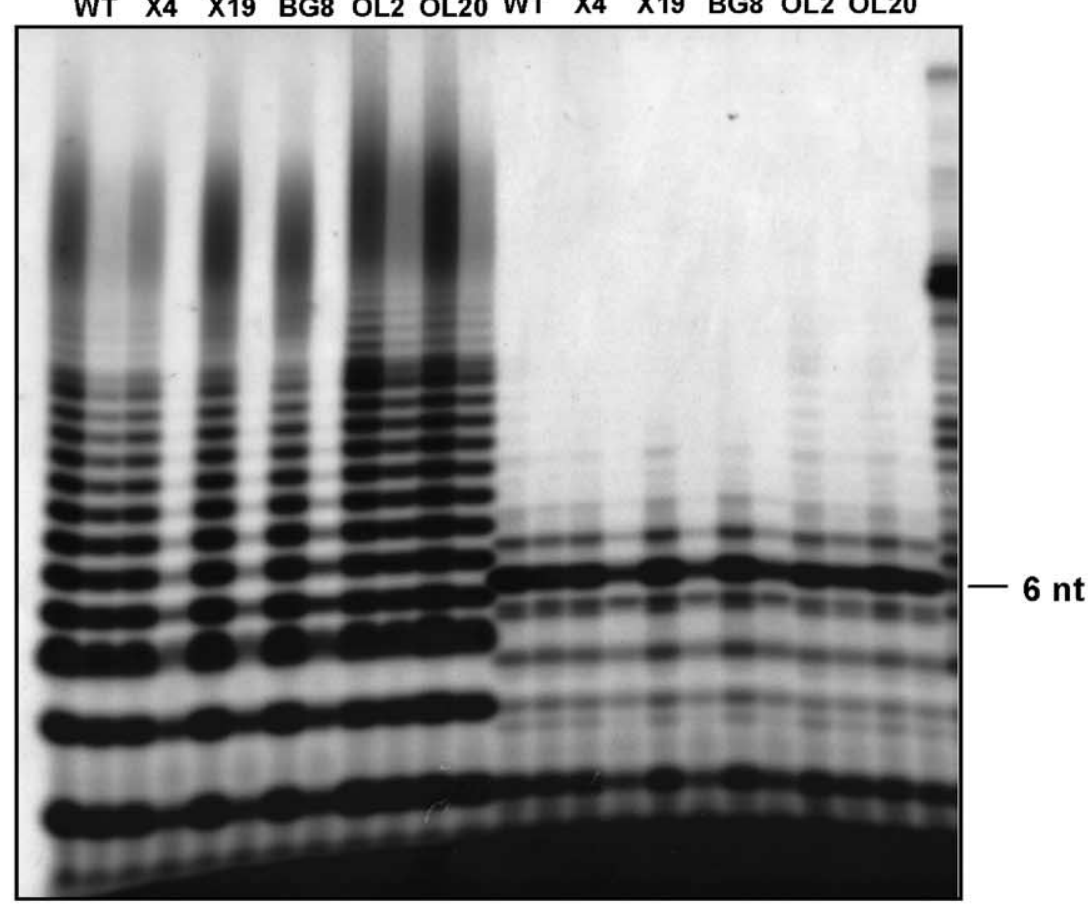

GAC

NTP

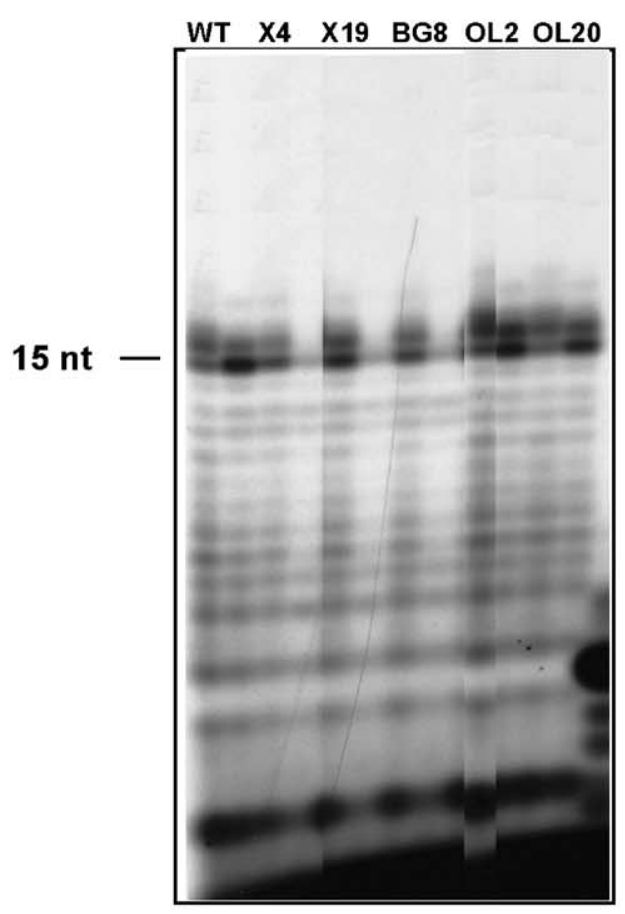

WT $\quad$ X4 $\quad$ X19 $\quad$ BG8 OL2 OL20

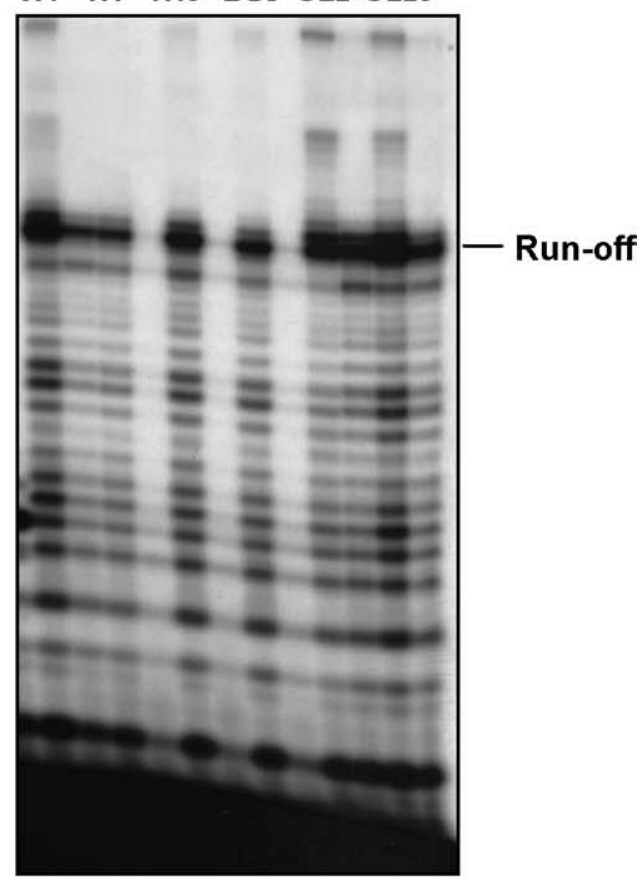

Figure 8. Transcription by different mutant polymerases. Transcription reactions contained $200 \mathrm{nM}$ duplex 48 -mer template, $200 \mathrm{nM}$ freshly prepared partially purified polymerase, and $50 \mu \mathrm{Ci} / \mathrm{ml}$ of $\left[\alpha^{32} \mathrm{P}\right] \mathrm{GTP}$. The NTP mix $(0.4 \mathrm{mM}$ each) for each set of lanes is indicated in the Figure. This template specifies three initial $\mathrm{G}$ residues, which give rise to a G ladder when GTP is the only NTP. Maximum extension with GTP + ATP should be six bases, and with GTP + ATP + CTP should be 15 bases. The runoff transcript with all four NTPs should be 24 bases. The transcription products were separated on a $20 \%$ polyacrylamide gel in TBE buffer with $8 \mathrm{M}$ urea and visualized by autoradiography. ${ }^{16}$ Pairs of samples containing no lysozyme or a $10: 1$ molar ratio of lysozyme to polymerase alternate in the order wild-type, X4 (A821T), X19 (A465T), BG8 (A702T), OL2 (M549I) and OL20 (G555A). 


\section{Effect of LH mutations on formation of long transcripts}

The elongation phase of transcription by LH and OL mutant polymerases was examined using as template a derivative of lambda DNA that contains a $\phi 10$ promoter for T7 RNA polymerase. We previously found that wild-type T7 RNA polymerase takes about 75 seconds to form a $15 \mathrm{~kb}$ transcript from this template, and that addition of lysozyme after elongation complexes have formed has little effect on elongation but stimulates pausing or termination at specific sites. ${ }^{16}$ Transcription reactions containing either no lysozyme or a 10:1 molar ratio of lysozyme to polymerase added 15 seconds after initiation were stopped at various times and the products analyzed by gel electrophoresis (Figure 9). The wild-type patterns were as described, ${ }^{16}$ with lysozyme stimulating pausing at P1 and greatly increasing termination at T1.

Transcription by the LH polymerase mutants X4 (A821T) and X19 (A465T) in the absence of lysozyme was similar to that of wild-type polymerase in the presence of lysozyme, except that the mutant polymerases accumulated RNA chains less rapidly than wild-type (Figure 9). When lysozyme was added 15 seconds after initiation, transcription by the LH mutant polymerases was severely reduced relative to wild-type, and what transcripts were made stopped at $\mathrm{P} 1$ rather than continuing on to terminate at $\mathrm{T} 1$. These results are consistent with the interpretation that LH polymerases are, on average, slower than wild-type to establish elongation complexes. Most wild-type polymerases establish elongation complexes and pass P1 within 15 seconds of the addition of nucleoside triphosphates $^{16}$ (Figure 9) but it appears that almost none of the LH mutant polymerases had made it past P1 by 15 seconds, the time lysozyme was added, since those RNA chains that were elongated stopped at P1 rather than T1. Although lysozyme may interfere with elongation by at least some LH mutant polymerases, ${ }^{27}$ the delay in establishing elongation complexes would be sufficient to account for the results. Thus, it seems that lysozyme-hypersensitive mutants in the absence of lysozyme are similar to wild-type lysozyme-polymerase complexes in delaying the establishment of elongation complexes. ${ }^{27-30}$

The SLH mutant polymerases Q852R and Q852H in the presence or absence of added lysozyme behaved about the same as wild-type in the absence of lysozyme, consistent with the main effect of these mutations being to prevent lysozyme binding (Figure 9).

Transcription by the LR mutant polymerase OL2 (M549I) in the absence of lysozyme appeared to give rise to two populations of transcription

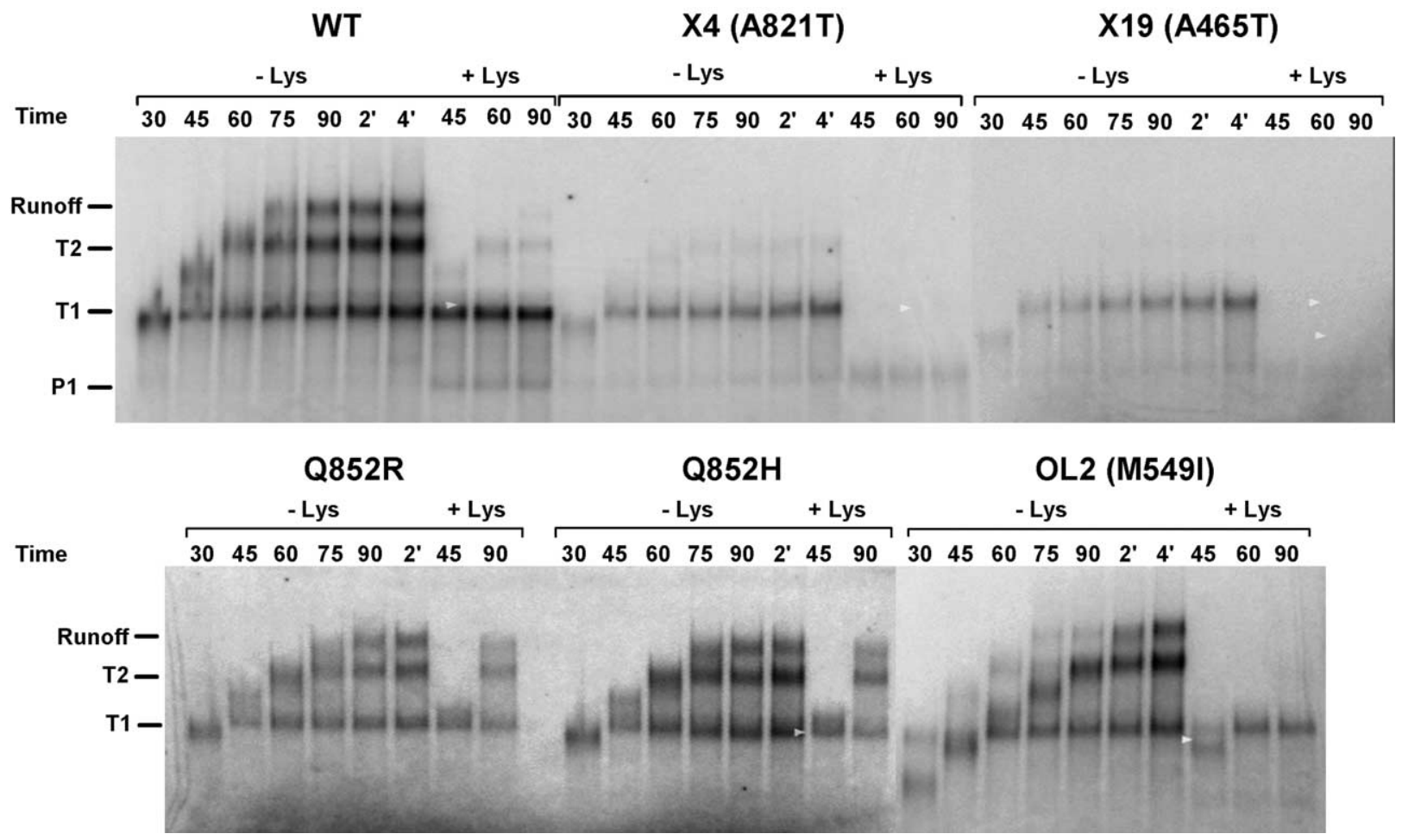

Figure 9. Elongation, pausing and termination by wild-type and mutant polymerases. Transcription reactions contained $6 \mathrm{nM}$ uncut $\lambda \phi 10 \mathrm{R} D \mathrm{DNA}$ and approximately $5 \mathrm{nM}$ partially purified polymerase. Reaction conditions, the P1, $\mathrm{T} 1, \mathrm{~T} 2$ and runoff transcription products, separation by electrophoresis through $1 \%$ agarose, and visualization by autoradiography have been described. ${ }^{16}$ As indicated in the Figure, samples were taken at intervals after initiation (seconds unless indicated minutes). Transcription was in the absence of lysozyme (-Lys) or with a $10: 1$ molar ratio of lysozyme to polymerase added 15 seconds after initiation (+Lys). The polymerases were wild-type, X4 (A821T), X19 (A465T), SLH1 (Q852R), SLH16 (Q852H) and OL2 (M549I). 
complexes: a minor fraction seemed to behave about like wild-type but the majority seemed to have had a longer than 15 seconds delay in establishing elongation complexes, which then elongated much like wild-type (Figure 9). When lysozyme was added at 15 seconds, most of the chains terminated at $\mathrm{T} 1$, as with wild-type polymerase. However, substantially fewer chains appeared to reach T1, relative to wild-type, probably because elongation complexes had not been established on a significant fraction of templates before lysozyme addition at 15 seconds. The transcription behavior of the OL2 (M549I) mutant polymerase suggests a possible slow equilibrium between two polymerase conformations that establish elongation complexes with different kinetics, although we cannot rule out possible contamination with wild-type polymerase.

\section{Pausing at the concatemer junction}

A strong pause site for transcription by T7 RNA polymerase is located near the right end of the concatemer-junction sequence of replicating T7 DNA, and lysozyme increases the length of the pause. ${ }^{16,31,32}$ It seems likely that a pause at this site is needed for initiation of the DNA maturation and packaging process, and that lysozyme stimulates maturation by prolonging the pause. ${ }^{16}$ If so, we would expect that, in the absence of lysozyme, LH mutants might pause longer at this site than wild-type, because LH mutants mature and package DNA with normal efficiency in the absence of lysozyme.

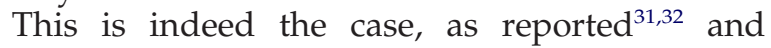
shown in Figure 10. With wild-type polymerase, the paused transcript was present by eight seconds and its amount changed little over the four minutes of the reaction, whereas a substantial amount of runoff transcript appeared by 15 seconds and increased steadily throughout the reaction. With LH mutants X4 (A821T) and X19
(A465T), the paused transcript appeared to reach steady state by about 14 seconds but the runoff transcript increased much more slowly than in wild-type, indicating a much longer pause. The amount of material at the position of the paused transcript increased gradually over the four minutes of the experiment, presumably because the pause was long enough that some of the paused complexes dissociated before elongation resumed. The OL2 (M549I) mutant polymerase behaved similarly to wild-type except for a delay in the paused transcript reaching steady state, consistent with the delay in transcription by the major fraction of OL2 polymerases (Figure 9).

\section{Discussion}

\section{Lysis}

The amidase activity of T7 lysozyme has an important role in the lysis of T7-infected cultures, apparently gaining access to the peptidoglycan layer through pores created by the T7 holin specified by gene 17.5.24 T7 lysozyme produced from a clone has little effect on Escherichia coli unless a membrane-disrupting agent is added to the culture, whereupon even small amounts of lysozyme cause the culture to clear. ${ }^{15}$ The delayed and gradual clearing of cultures observed after infection with T7 mutants that lack amidase activity is presumably due to action of the holin and perhaps auxiliary factors, which allows release of much of the cell contents but only inefficient release of phage particles. Although needed for release, T7 lysozyme is not needed for infectivity of T7 phage particles, either by action on the phage particle or by action on the cell wall as part of the entry process, because phage particles produced in the total absence of lysozyme and released from cells by detergent are fully infective.

The mechanism for triggering the characteristically abrupt lysis of $\mathrm{T} 7$ cultures at the end of

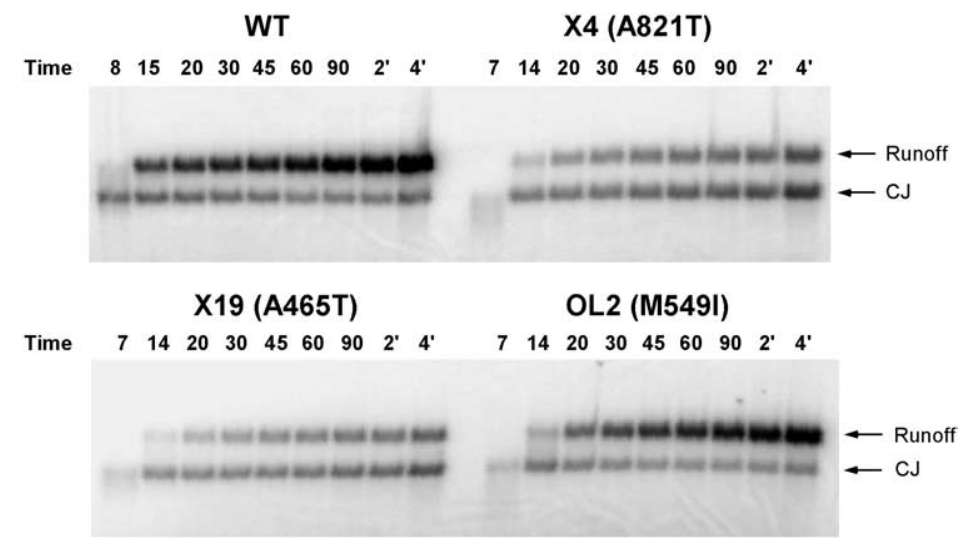

Figure 10. Transcription and pausing at the concatemer junction. The template for transcription was EcoRI-cut plasmid pAR4716, which contains the concatemer junction and flanking sequences of T7 DNA. ${ }^{16}$ The paused product $(\mathrm{CJ})$ is about 700 bases and the runoff product is about $1.2 \mathrm{~kb}$. Reactions contained $20 \mathrm{nM}$ template DNA and $50 \mathrm{nM}$ partially purified polymerase. The reaction mixtures were preincubated for one minute at $37^{\circ} \mathrm{C}$ before NTPs were added, and reactions were sampled at intervals after initiation (seconds unless indicated minutes). The RNA products were separated by electrophoresis through a $2 \%$ agarose gel. 
infection remains something of a mystery. Lysozyme and holin appear not to be sufficient by themselves, since T7 mutants with defects in replication invariably have a delayed or gradual lysis even though protein synthesis (and thus synthesis of lysozyme and holin) appears to be normal. ${ }^{12,33}$ The abrupt lysis of wild-type T7 is in contrast to bacteriophage $\lambda$, where lysis is more gradual and the timing appears to be solely determined by the action of holin. ${ }^{34}$ The inhibition of amidase activity when lysozyme is in a complex with polymerase ${ }^{17}$ seems unlikely to have a role in the timing of T7 lysis, since LH,AK6 double mutants (which do not form lysozyme-polymerase complexes) produce essentially normal plaques. Possibly, holin protein by itself is capable of forming pores only slowly, and something associated with replication or packaging somehow stimulates rapid pore formation at the appropriate time. An intriguing possibility is that something associated with the hairpin structure generated in the packaging process $^{25}$ is somehow involved, since plasmids that carry the $\phi \mathrm{OR}$ replication origin and the hairpin site near the right end of T7 DNA can stimulate premature lysis after T7 infection ${ }^{35}$ (F.W.S., unpublished results), and deletion of the hairpin site in T7 DNA delays lysis. ${ }^{36}$

\section{Possible roles of polymerase in initiating replication}

The level of lysozyme produced during T7 infection appears to be carefully controlled through a feedback loop. ${ }^{15}$ A fixed pool of polymerase molecules is produced by early gene expression, and these polymerases transcribe the T7 late genes, including T7 lysozyme. The newly made lysozyme binds to the polymerase and reduces transcription capacity, shutting off transcription of the lysozyme gene preferentially relative to genes for phage particle proteins and thereby limiting the production of lysozyme. When higher than normal levels of lysozyme are produced during infection by transcription of a cloned gene under control of a strong T7 promoter in a multi-copy plasmid, the excess lysozyme can suppress late transcription sufficiently to prevent growth ${ }^{15}$ (Table 2 ).

The lysozyme-polymerase complex clearly has a role in replication and maturation of T7 DNA. Lysozyme or polymerase mutants unable to form this complex produce less T7 DNA, mature their DNA less efficiently and produce only about a third as many infective phage particles as wildtype (Figures 1-3). However, the defects in such mutants are suppressed by compensating polymerase mutations that provide essentially normal replication, packaging and phage production even though lysozyme-polymerase complexes are not formed and transcription of T7 DNA is not shut off (Figures 5 and 6). Although transcription shuts off in a wild-type infection as replication begins, continued active transcription does not interfere with replication in these mutants, and the primary effect of the lysozyme-polymerase complexes in stimulating replication must, therefore, be due to something else.

Surprisingly, all of the mutant polymerases that supported wild-type levels of phage production in the absence of an interaction with lysozyme were hypersensitive to inhibition by lysozyme and would thus be unable to grow if the phage produced wild-type lysozyme. ${ }^{3}$ This result indicates that two mutually exclusive varieties of T7 have approximately equivalent growth rates and levels of phage production: wild-type, which forms lysozyme-polymerase complexes that stimulate replication and packaging, and double mutants with a lysozyme-hypersensitive polymerase plus a lysozyme that has lytic activity but is unable to bind polymerase. It seems likely that T7-like phages equivalent to the double mutants exist in nature. Their polymerase would be homologous to T7 RNA polymerase but would not form a complex with their lysozyme, which would not necessarily be homologous to T7 lysozyme. Salmonella phage SP6 (GenBank accession no. NC_004831) appears to be an example, as it specifies an RNA polymerase homologous to T7 RNA polymerase but no protein homologous to T7 lysozyme.

T7 specifies most of the proteins needed for replication, which is extremely rapid during infection $^{33}$ (Figures 2-5), presumably due to the generation of many simultaneous replication forks. The replication origins identified in T7 DNA are associated with promoters for T7 RNA polymerase, indicating that the specificity of T7 RNA polymerase for its own promoters directs the newly made replication complexes to T7 DNA.,4 Lysozyme-polymerase complexes or lysozymehypersensitive polymerase mutants apparently act to increase the rate of initiation of replication. A claim that lysozyme is needed for initiation of replication at secondary origins ${ }^{4}$ seems to be incorrect, as both primary and secondary origins in plasmids were used after infection with a lysozyme deletion mutant (Figure 4). As expected, if lysozyme-polymerase complexes stimulate initiation, replication from both primary and secondary origins in plasmids was lower during infection by the lysozyme-deletion mutant than during infection by wild-type.

The role of T7 RNA polymerase in initiation of replication is still not well defined. Previous work indicated that T7 RNA polymerase can provide primers for rightward replication from the primary origin of replication of T7 DNA in vivo ${ }^{6}$ and in an in vitro system containing purified T7 RNA polymerase, T7 DNA polymerase and the T7 primase/ helicase. ${ }^{5,37}$ It was postulated that T7 RNA polymerase catalyzes the establishment of replication complexes by synthesizing a primer that can be extended by T7 DNA polymerase and/or by opening the DNA for binding by the primase/helicase. Since only certain promoters are associated with replication origins, some features of the DNA 
sequence in the region are presumably involved in making primers accessible to the DNA polymerase, facilitating opening of the DNA for binding by the primase/helicase, or recruiting components of the replication complex to the site.

In view of what is known or postulated, how could the lysozyme-polymerase complex (or lysozyme-hypersensitive polymerases in the absence of lysozyme) be acting to stimulate initiation of replication? Bound lysozyme has little effect on promoter binding but decreases the affinity for NTPs in the initiation complex, reduces the rate of nucleotide addition, and increases the dissociation of short RNAs from the template, possibly by destabilizing the open initiation complex. ${ }^{27-30}$ These effects make it harder to synthesize RNAs that are long enough to trigger the formation of processive elongation complexes, resulting in longer residence at the promoter, increased production of short, abortive transcripts, and substantial decreases in full-length transcripts. The greater numbers of abortive transcripts by themselves seem unlikely to be responsible for stimulating replication, since abortive transcripts would be expected to increase at all promoters, not just those in replication origins. Conceivably, bound lysozyme (and lysozyme-hypersensitive polymerases) could accentuate transcriptional pausing at specific sites downstream of replication promoters to facilitate interactions necessary to initiate replication. Such pausing has been proposed to account for the observed sites of transition from RNA to DNA downstream of replication origins, ${ }^{37}$ although evidence for specific transcriptional pause sites has not been reported.

A third possibility is that polymerase at a replication promoter interacts with the replication complex during the period before a transcription elongation complex forms, and that bound lysozyme (or lysozyme-hypersensitive polymerases) stimulates replication by prolonging residence at the promoter, thereby providing more time for a replication-initiation complex to form. However, no interactions between polymerase and elements of the replication complex have been reported, and a search for polymerase mutants defective in replication but not transcription was not successful. ${ }^{3}$ Perhaps the frequency of this type of mutation relative to the other types found in the selection and screening protocol may have been too low for them to have been found, and other protocols ${ }^{3}$ might have a better chance of finding them. Clearly, more information is needed before the stimulation of replication by the lysozymepolymerase interaction can be properly understood.

\section{Role of polymerase in DNA maturation and packaging}

Maturation and packaging of T7 DNA begins with the formation of the mature right end of T7 DNA by cutting the concatemer at the right end of the $160 \mathrm{bp}$ concatemer junction that forms the terminal repetition of mature T7 DNA. ${ }^{7,8,25,38}$ A terminase formed by the gene 18 and gene 19 proteins in a complex with phage proheads is responsible for making this cut, which does not occur in mutants unable to make proheads or the gene 18 or gene 19 proteins. ${ }^{39,40}$ The newly created right end of T7 DNA enters the prohead and the packaging process triggers a conversion of proheads to mature heads, with the loss of scaffolding protein. ${ }^{12,40}$ Polymerase is required for making this cut and initiating packaging, because transcription through the concatemer junction is required for packaging, ${ }^{8}$ and T7 strains with polymerase mutations in the vicinity of amino acid residues 173-181 make T7 proteins and replicate T7 DNA normally but fail to cut the concatemers or convert proheads to mature heads ${ }^{3}$ (J. J. Dunn \& F.W.S., unpublished results). These mutant polymerases also fail to pause at the sequence TATCTGTT, a known pause site for T7 RNA polymerase at the right concatemer junction ${ }^{16,31,32}$ (Figure 10). Weak suppressors of the growth deficiency of T7 strains having such mutant polymerases arise in T7 gene 19, suggesting a direct interaction between polymerase and terminase in the initiation of packaging $^{3}$ (J. J. Dunn, personal communication). A reasonable model that integrates these observations is that a transcription complex paused at the right end of the concatemer junction interacts with the complex of prohead and the gene 18 and gene 19 proteins to initiate maturation and packaging. Apparently, concatemer DNA itself has few if any ends, and a mechanism to generate them is needed if significant packaging is to occur.

This model is consistent with the data known to us and has many satisfying elements. Requiring interaction of the packaging complex with a paused transcription elongation complex uses the specificity of T7 RNA polymerase to select T7 DNA for packaging and directs the packaging complex to the appropriate site in concatemer DNA. Requiring an elongation complex prevents packaging from starting at polymerases bound at promoters. Requiring pausing prevents packaging from starting at any elongating polymerase regardless of position. Presumably, a pause allows recruitment of the packaging complex, involving an interaction between polymerase and the gene 19 protein, and as pauses become shorter the efficiency of recruitment decreases. Thus, wildtype lysozyme-polymerase complexes or lysozyme-hypersensitive mutants have the longest pauses and package DNA most efficiently, wildtype polymerase not in a complex with lysozyme pauses only briefly and packages less efficiently, and polymerase mutants that do not pause at the end of the concatemer junction do not initiate maturation and packaging.

Presumably, most of the transcription complexes involved in packaging would initiate RNAs at the $\phi \mathrm{OR}$ promoter $708 \mathrm{bp}$ from the position of the pause sequence in the concatemer junction. The 
$\phi \mathrm{OR}$ promoter has the class III consensus sequence, so transcription from it is presumably relatively resistant to inhibition by lysozyme, and this promoter is associated with what appears to be the strongest of the secondary origins of replication of T7 DNA (Figure 4). ${ }^{4}$ The only potential protein-coding sequence between the $\phi \mathrm{OR}$ promoter and the right end of T7 DNA is putative gene 19.5, which would specify a small protein of 49 amino acid residues, if indeed it is made. ${ }^{2}$ Also between the $\phi \mathrm{OR}$ promoter and the concatemer junction is the site of the hairpin structure that initiates rightward replication across the concatemer junction, apparently to duplicate the terminal repetition as part of the packaging process, so that genomes adjacent to the packaged genomes are not wasted in creating the terminal repetition (J. J. Dunn \& F.W.S., unpublished results) ${ }^{25}$ A replication fork initiated at the hairpin would discontinuously replicate the DNA strand that is the template for transcription, and a transcription elongation complex could not reach the pause site unless the breaks in the discontinuously replicated strand had been sealed. Thus, initiating packaging from a paused elongation complex would ensure that packaging starts on an intact end.

\section{Model for pausing and termination}

The eight base sequence (C/T)ATCTGTT in the non-template strand triggers pausing by T7 RNA polymerase and related phage polymerases, and, if followed by a T-rich sequence, causes termination $6-8 \mathrm{bp}$ past the recognition sequence. ${ }^{31,32,41-44}$ The structure of an elongation complex that contains the non-template strand ${ }^{22}$ suggests a possible model that is consistent with effects of polymerase mutations and a large body of biochemical work on pausing and termination at $(\mathrm{C} / \mathrm{T}) \mathrm{ATCTGTT}$ (Figure 11A).

Examination of the structure indicates that amino acid residues K164, Q169, R173, Y178 and Y385 of the polymerase interact with the nontemplate strand that is displaced by the 7-9 bp RNA-DNA duplex in the transcription bubble adjacent to the site of nucleotide addition (Figure 11B). It is striking that these are exactly the amino acid residues affected by mutations known to prevent pausing or termination at the (C/T)ATCTGTT recognition sequence, and all but Q169 are highly conserved in the polymerases of the T7-like phages. Thus, the R173C and Y385A mutations, and deletion of amino acid residues $172-173,173-174,163-169$ or $178-193$, are all known to prevent pausing or termination at this site, as are insertions of a glycine residue after amino acid residue 180 or $181 .^{32,45}$ The glycine insertions might disrupt a short helix and affect the R173 or Y178 interaction with the DNA. Residues 169-181 are part of a region referred to as subdomain $\mathrm{H}^{22}$ or flap, ${ }^{23}$ which is newly formed by a massive refolding in the transformation to the elongation complex and which forms part of the RNA exit channel and non-template DNAbinding site.

If the polymerase were to bind specifically to the $(\mathrm{C} / \mathrm{T}) \mathrm{ATCTGTT}$ sequence in the non-template strand when it emerged into the transcription bubble and thereby lock it in place, extension of the RNA chain could continue only by scrunching the non-template strand into space adjacent to the site of nucleotide addition (Figure 11A). Extension of the RNA would also be accompanied by extrusion of unpaired template strand at the trailing end of the RNA-DNA duplex, because the RNA would be displaced into the exit channel and the dissociating template strand would not be able to re-associate with its specifically bound complement (Figure 11A). If six to eight additional bases were added to the RNA chain before no more unpaired DNA could be accommodated, synthesis would stall with these newly added bases in the paused RNA-DNA duplex. The polymerase might also have sequence-specific interactions with the extruded, unpaired template-strand recognition sequence, which might help to stabilize the paused complex. The structure of the elongation complex suggests that amino acid residues D388 and R357, which are highly conserved in the phage polymerases, could interact with unpaired template-strand bases immediately upstream of the RNA-DNA duplex, and the rest of the thumb domain including amino acid residues 365-374, which are disordered in the structure, is close enough that some of them may also have interactions with the extruded template strand (Figure 11B). Consistent with this possibility, the D388A mutation significantly reduces termination at a sequence that contains the recognition sequence, and deletion of residues 359-381 almost eliminates pausing and termination. ${ }^{45}$ The effect of R357 mutations on pausing is unknown.

This model readily explains the observation by Hartvig \& Christiansen ${ }^{41}$ that thymine residues just downstream of the recognition sequence in the non-template strand had chemical reactivity characteristic of a single-strand conformation but thymine residues within the recognition sequence (which would be tightly bound to the polymerase) were not reactive. They found no transcriptioninduced reactivity in the template strand, consistent with the idea that the extruded template strand in the paused complex is specifically bound by polymerase. Song \& $\mathrm{Kang}^{44}$ did a more detailed analysis of the reactivity of unpaired thymine residues of the non-template strand as elongation complexes were moved step-wise across the recognition sequence. They found reactivity consistent with a moving transcription bubble of about ten unpaired bases in the non-template strand until the transcription complex reached a point where the entire TATCTGTT sequence should have become single-stranded, when an abrupt loss of reactivity occurred within the recognition sequence, consistent with its becoming tightly 


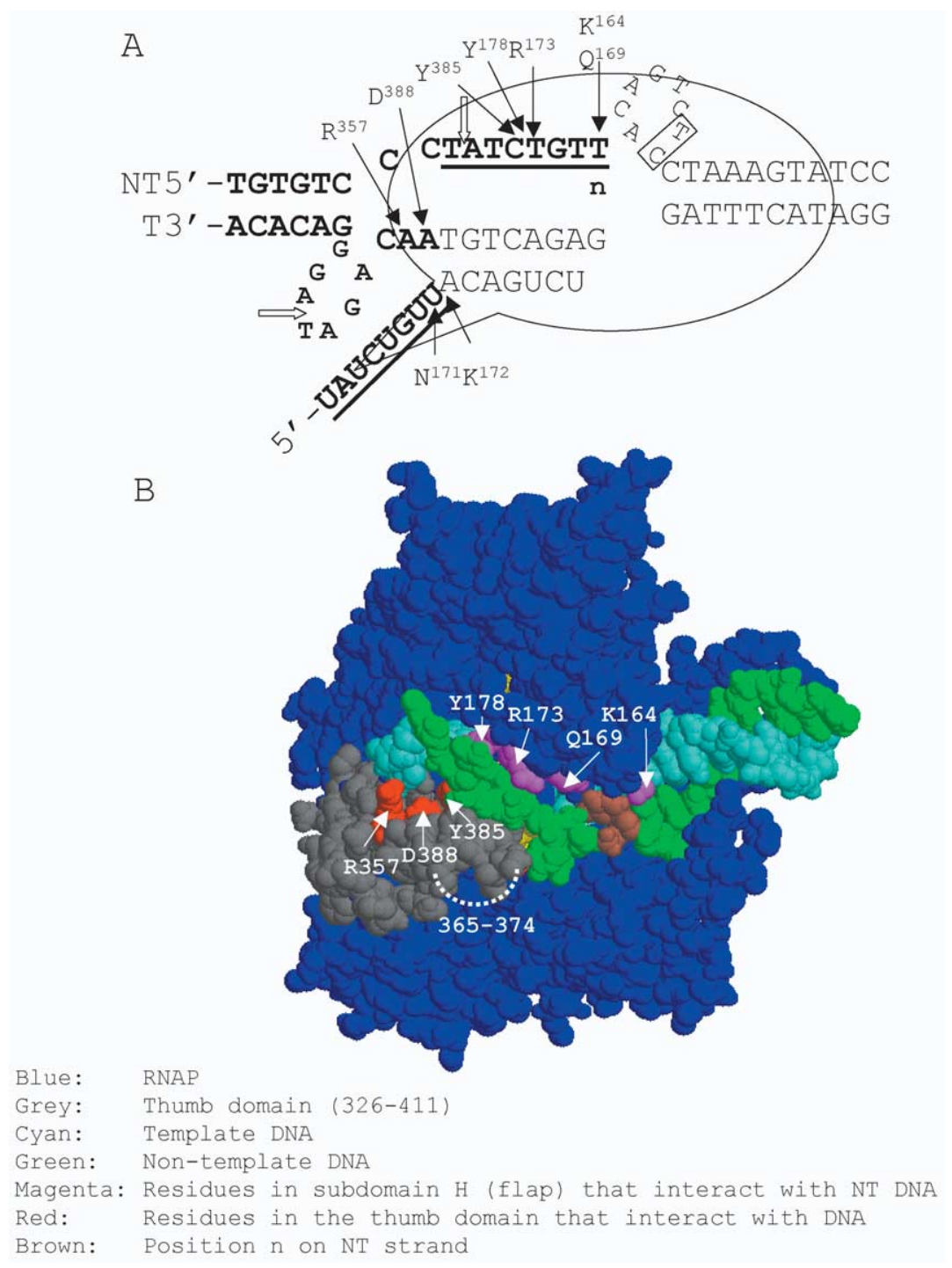

Figure 11. Model for T7 RNA polymerase paused at the TATC TGTT recognition site of the T7 concatemer junction site. A, The polymerase is represented as an ellipse with an extension to indicate the RNA exit channel. The TATCTGTT pause sequence in the non-template strand and in the RNA are underlined; sequences conserved in T7, T3, Ye03-12 and K11 DNAs are in bold. Thin arrows above the nontemplate strand indicate residues of subdomain $\mathrm{H}$ (flap) or the thumb domain that are postulated to interact with the recognition sequence in the non-template strand or the extruded template strand to prevent the usual movement of the non-template strand upon nucleotide addition and stabilize the paused complex. Addition of seven bases past the pause sequence is shown in a seven base RNA-DNA hybrid waiting for addition of a $C$ residue. The postulated inability of the nontemplate strand to move, coupled with continued unwinding of the DNA and movement of the template strand, generates a singlestrand loop of non-template DNA ahead of the RNA-DNA hybrid and a loop of template DNA behind it, which is postulated to have sequence-specific interactions with residues of the thumb domain. The boxed TC in the non-template strand shows the position of the most common final nucleotide in RNAs paused or terminated at this site. ${ }^{32}$ Black arrows indicate the positions of the cuts that generate the right end of mature T7 DNA in packaging. B, Structural model of the polymerase elongation complex, as determined by Yin \& Steitz, ${ }^{22}$ in approximately the orientation diagrammed in A. The DNA and RNA are those of the complex studied by Yin and Steitz, and the structure does not model the scrunched non-template nor extruded template strands postulated in A. Positions of residues postulated to interact with the recognition sequence in the non-template or extruded template strand are indicated.

bound to the polymerase (although interpreted by them as collapse of the transcription bubble). No such loss of reactivity was seen in transcription of an otherwise identical sequence with two changes in the recognition sequence to give TActTGTT, a sequence that does not cause pausing. Song \& Kang $^{44}$ also found that addition of the last two nucleotides before termination was slower and required higher concentrations of NTPs, consistent with increased difficulty of adding nucleotides as space available for scrunching of the non-template strand becomes limiting.

As expected, if sequence-specific interactions between the polymerase and recognition sequence are responsible for pausing, most base changes within the recognition sequence eliminate pausing or termination, whereas a variety of changes in nearby residues have little effect. ${ }^{42,43}$ Effects of changing only one strand of a heteroduplex indicate that both the template and non-template recognition sequences are needed for pausing, lending support to the idea that sequence-specific interactions with the polymerase occur with each of the separated strands of the recognition sequence. The increase in termination relative to pausing when the downstream six to eight bases of the non-template strand are T-rich ${ }^{31,41}$ is easily explained because the RNA specified by these residues would be in the RNA-DNA hybrid of the paused complex (Figure 11A), and the destabilizing $U$ residues would increase dissociation of the RNA. The model also provides a natural explanation for the effects of incorporating base analogs, ${ }^{41,43}$ the observation that extra $\mathrm{A}$ residues are incorporated by slippage at runs of $\mathrm{T}$ close to the termination residue, ${ }^{43}$ and the 
requirement for having double-stranded template for at least $8-12$ bp downstream of the termination site. $^{32}$

Although lysozyme and lysozyme-hypersensitive mutants can substantially increase pausing at the $(\mathrm{C} / \mathrm{T}) \mathrm{ATCTGTT}$ recognition sequence, they apparently do not affect termination at sites that act through stem-loop structures in the RNA, such as the natural $T \phi$ termination signal or $r r n \mathrm{~B} \mathrm{~T}_{2} \cdot{ }^{16,31}$ A possible mechanism by which lysozyme or lysozyme-hypersensitive mutants might increase pausing at the $(\mathrm{C} / \mathrm{T}) \mathrm{ATC}$ TGTT recognition sequence is presented below in section Biochemical effects of lysozyme binding and mutant polymerases.

\section{Packaging in T7-like phages, and the consensus sequence for pausing}

The T7-like phages T7 (GenBank accession no. V01146), ${ }^{2}$ T3 (GenBank accession no. NC_003298), ${ }^{46}$ A1122 (GenBank accession no. NC_004777), ${ }^{47}$ YeO3-12 (GenBank accession no. NC_001271) ${ }^{48}$ and K11 (GenBank accession nos. X01769 and $\mathrm{X} 01770)^{49}$ all have an eight base recognition sequence for pausing at the right end of the concatemer junction in the sequence CCCTIATCTGTT (where the recognition sequence is underlined and the position of the mature right end is indicated by "|"). Phage gh-1 (GenBank accession no. NC_004665) $)^{50}$ is also closely similar to T7 in gene content and organization, but the sequence flanking its mature right end is CICCTATCTGTA, a sequence that differs from the other T7-like phages only in the last base of the recognition sequence and a three-base shift in the location of the mature right end relative to the pause sequence. The more distantly related but still T7-like phage SP6 (GenBank accession NC_004831) has its mature right end in the sequence GGCTAITCTGTT, which contains the same pause-recognition sequence as T7 but a divergent upstream sequence and a one-base shift of the mature right end relative to the pause sequence. In each of these phage DNAs (except K11, most of whose sequence is unknown), the concatemer-junction site is the only place in concatemer DNA that contains any of the potential pause-recognition sequences (C/T)ATCTGT(T/A), except for YeO3-12, which has the sequence TATC TGTA $128 \mathrm{bp}$ past the right-end sequence, where it could not be transcribed by T7 RNA polymerase except by escape from the normal right-end pausing and packaging site. None of the pauserecognition sequences at the concatemer junctions is followed by a T-rich sequence, indicating that they are primarily pausing and not termination sites. Interaction of the paused polymerase and prohead-terminase complexes in the different phages apparently cuts the DNA at slightly different positions relative to the pause-recognition sequence, depending on the specifics of the interaction, but the packaging mechanism appears to be highly conserved.
The pause sequence in the gh- 1 packaging site differs from pausing and termination sites previously studied in having an $\mathrm{A}$ in the eighth position. This same eight base sequence occurs in pBR322 DNA at a site that is used to initiate packaging when the cloned fragment of T7 DNA that directs packaging does not contain the concatemer-junction pause sequence. ${ }^{38}$ In this situation, a small fraction of packaged right ends also arise about 300 bases past this site, ${ }^{38}$ where an eight base sequence is found that differs only in having $G$ in the eighth position. It seems that the consensus sequence for pausing should be expanded to include at least A and possibly $G$ in the eighth position.

A search of the complete genomes of the above six T7-like phages identified a total of 26 sites containing bases 2-7 of the eight base recognition sequence, namely ATCTGT. Six of these sites are packaging sites and five of them are not expected to be transcribed by the phage RNA polymerase. The remaining 15 sites are all transcribed by the phage RNA polymerase, so none of them should be a strong pause site, which would interfere with gene expression or compete for packaging. Four of the 15 sites have $G$ in the first position, which is known to prevent termination. ${ }^{42,43}$ Another five have a favorable $\mathrm{C}$ or $\mathrm{T}$ in the first position but all have $C$ in the eighth position, indicating that $C$ in the eighth position of an otherwise consensus sequence does not give efficient pausing. The remaining six sites have $\mathrm{A}$ in the first position, which reduced but did not eliminate in vitro termination at a consensus site with $\mathrm{T}$ in the eighth position. ${ }^{42}$ None of these sites has $\mathrm{T}$ in the eighth position: one has $\mathrm{C}$, which should eliminate pausing, four have $\mathrm{G}$ and one has $\mathrm{A}$. Although $\mathrm{A}$ in the eighth position apparently enables pausing with $\mathrm{T}$ in the first position in the gh- 1 and pBR322 sites, neither $G$ nor $A$ in the eighth position appears to enable efficient pausing with $\mathrm{A}$ in the first position. Provisionally, the consensus eightbase sequence (C/T)ATCTGT(T/A) would appear to give the most efficient, physiologically relevant pausing. Whether pausing with $\mathrm{A}$ in the first position and $\mathrm{T}$ in the eighth, or with $\mathrm{C}$ or $\mathrm{T}$ in the first position and $G$ in the eighth is biochemically or physiologically significant has yet to be determined. All but one of the possible single-base variants in bases 2-7 of the consensus sequence are present in the transcribed region of one or more of the six T7-like phage genomes, lending further support to the specificity of this sequence for physiologically relevant pausing.

\section{Biochemical effects of lysozyme binding and mutant polymerases}

The amino acid changes that create lysozymehypersensitive and lysozyme-resistant polymerases are interspersed and widely distributed in the amino acid sequence (Table 3). Mutations tend to cluster and changes in adjacent amino acid 
residues can have opposite effects (residues 702-703, 775-776, and 827-828). Combining the lysozyme-hypersensitive mutation A702T with the adjacent lysozyme-resistant A703T resulted in a lysozyme-resistant double mutant. How are these observations to be interpreted?

Previous work indicates that wild-type polymerase is in equilibrium between two conformations, a predominant, catalytically active conformation in which the C-terminal residues are folded inward beneath the active site (referred to as C-in) and a much less active conformation where the C-terminal residues are flipped out and exposed to solvent (referred to as C-out). ${ }^{27,29}$ Structures of the polymerase, promoter complex, initiation complex and elongation complex all show the C-terminal residues folded in, whereas the lysozyme-polymerase complex shows them flipped out. ${ }^{18,20-23}$ C-terminal residues in the C-out conformation are much more susceptible to cleavage by carboxypeptidase, which provides a convenient assay of the C-out conformation in solution. ${ }^{27}$ Carboxypeptidase sensitivity measurements show that lysozyme bound to wild-type polymerase shifts the equilibrium toward the C-out conformation. ${ }^{27}$ Biochemical studies have shown that mutation or deletion of the C-terminal few residues substantially reduces catalytic activity, ${ }^{51-53}$ consistent with the interpretation that inwardly folded C-terminal residues stabilize the active site. Thus, at least some effects of lysozyme are plausibly due to its effect on the C-in/C-out equilibrium. The binding site for T7 lysozyme is some distance from the C-terminal residues or the active site, ${ }^{18}$ implying that the effect of bound lysozyme on the C-in/C-out equilibrium is transmitted through subtle changes in the structure of the polymerase. ${ }^{27}$

After transition to the elongation complex, lysozyme has little effect on elongation by wildtype polymerase, except to increase pausing and termination at the $(\mathrm{C} / \mathrm{T}) \mathrm{ATCTGTT}$ recognition sequence. ${ }^{16,31,32}$ The substantial rearrangement of the polymerase and the association of newly synthesized RNA with the exit channel apparently stabilize the catalytic site of the elongation complex sufficiently to provide resistance to possible effects of bound lysozyme during processive elongation. ${ }^{27}$ When specific interactions with the $(\mathrm{C} / \mathrm{T}) \mathrm{ATC}$ TGTT recognition sequence cause the elongation complex to pause (as postulated in our model for pausing and termination), perhaps the duration of the pause is related to the C-in/C-out equilibrium, and bound lysozyme increases the pause by shifting the equilibrium toward C-out.

Many of the lysozyme-hypersensitive polymerase mutants listed in Table 3 are more sensitive than wild-type to carboxypeptidase inactivation in the absence of lysozyme, and many of the lysozyme-resistant mutants are more resistant than wild-type to carboxypeptidase inactivation in the presence of lysozyme, consistent with the idea that one mechanism by which mutations cause lysozyme hypersensitivity or resistance is to affect the $\mathrm{C}$-in/C-out equilibrium of the polymerase (R. Sousa, personal communication). The lysozyme-hypersensitive mutations that lengthen pausing at the $(\mathrm{C} / \mathrm{T}) \mathrm{ATCTGTT}$ recognition sequence in the absence of lysozyme are of the type that increase the sensitivity to carboxypeptidase, again suggesting that a shift in the $\mathrm{C}$-in/C-out equilibrium toward $\mathrm{C}$-out increases the duration of the pause.

Lysozyme-hypersensitive and resistant mutants exhibit other types of behavior as well (R. Sousa, personal communication), indicating that an effect on the $\mathrm{C}$-in/C-out equilibrium is not the only way mutations cause lysozyme hypersensitivity or resistance. In particular, the lysozyme-hypersensitive mutant X60 (G235D) (and presumably BG14 (R231H) as well) appears not to affect the $\mathrm{C}$-in/C-out equilibrium but to have a deficiency in promoter melting ( $R$. Sousa, personal communication), consistent with its location in a polymerase structure important for promoter melting. ${ }^{30,54,55}$ As with mutations affecting the $\mathrm{C}$-in/C-out equilibrium, the mutation affecting promoter melting both delays the establishment of lysozyme-resistant elongation complexes and compensates for lack of a lysozyme-polymerase complex during T7 growth. The stimulation of T7 growth in the absence of an interaction with lysozyme is presumably due to a stimulation of replication, as mutations that affect promoter melting might be expected to have little effect on pausing or packaging. Stimulation of replication by two different types of lysozyme-hypersensitive mutation, both of which increase residence at the promoter but by entirely different mechanisms, lends support to the idea that longer residence of polymerase at the promoter may have a role in stimulating replication.

Based on our observations that lysozyme interferes with the transition from initiation to elongation complex but does not affect processive elongation (except to stimulate termination at specific sites), we previously postulated that bound lysozyme may interfere with a conformational change involved in transition to the elongation form (and might stabilize conversion back to the initiation conformation to enhance termination). ${ }^{16}$ However, structures determined since then show that the conformational rearrangement between the initiation and elongation complexes is extensive but the binding site for lysozyme is little changed. ${ }^{18,22}$ Thus, it seems unlikely that lysozyme binding has much effect on this large conformational rearrangement. Rather, changes in the $\mathrm{C}$-in/C-out equilibrium and the stability of the open complex during initiation appear sufficient to explain the lysozyme inhibition of transcription (and properties of many lysozyme-hypersensitive and resistant mutants): the lower affinity for NTPs and newly made short RNAs in the presence of lysozyme ${ }^{27,29,30}$ makes it more difficult to synthesize and retain 
RNA chains that are long enough (8-14 nt) to trigger the transformation to a processive elongation complex. ${ }^{22,23}$

\section{Materials and Methods}

\section{Bacteria, phage strains and plasmids}

E. coli strains BL21, BL21(DE2), BL21(DE3) and HMS174 ${ }^{56}$ were used as hosts for plasmids and for T7 infection. Wild-type T7 and procedures for working with it have been described. ${ }^{33}$ B25P medium is the fully defined B2 minimal medium containing $0.8 \mathrm{mM}$ phosphate, five times the concentration that would limit growth at $A_{600 \mathrm{~nm}} \sim 0.5 .^{57}$ The location of genes and genetic elements in the nucleotide sequence of T7 DNA are given by Dunn \& Studier ${ }^{2}$ and Moffatt et al. ${ }^{58}$ Fragments of T7 DNA were cloned in the BamHI site of pBR322 $2^{59}$ essentially as described. ${ }^{60}$ Properties of different types of mutant polymerases and lysozymes, and of T7 phages containing different combinations of mutations are summarized in Tables 1, 3 and 4.

Sequencing of plasmid or phage DNAs was performed using either Sequenase (US Biochemical) and deoxyadenosine $5^{\prime}-\left[\alpha-{ }^{35}\right.$ S]thiotriphosphate labeling, or ABI Prism ${ }^{\mathrm{SM}}$ dye terminator cycle sequencing kits (Perkin-Elmer), priming with synthetic oligonucleotides.

\section{Lysozyme clones and lysozyme mutants}

The lysozyme mutations $\Delta 3.5$, AK6 and AFK136 were first constructed in plasmids and then transferred to T7 phage by homologous recombination. Base-pairs 10,706-11,161 of T7 DNA code for T7 lysozyme (gene 3.5). ${ }^{2}$

The $\Delta 3.5$ mutation, which removes the coding sequence for amino acid residue 6 to the end of T7 lysozyme, was constructed by deleting base-pairs 10,72411,162 of T7 DNA and replacing them with a $10 \mathrm{bp}$ BamHI linker (CGGGATCCCG). If the fragments joined without any gain or loss of bases, the first five amino acid residues of lysozyme would be fused in-frame through a linker of 24 amino acid residues to the 121 amino acid residues of the gene 3.8 protein, which would also be produced from its own translation initiation site. If gain or loss of one or two bases in the joining process changed the reading frame, translation from the lysozyme start site would produce peptides of eight to ten amino acid residues.

To construct $\Delta 3.5$, plasmid pAR4501, which carries an AvaI-BglII fragment of T7 DNA $(10,513-11,519)$ cloned into the AvaI and BamHI sites of pBR322, was cut with DraI and AseI, which cut after base-pairs 10,723 and 11,162 in T7 DNA and at a few sites in pBR322. After filling in the AseI overhang, BamHI linkers were attached and the fragments were further digested with BamHI plus two enzymes that cut only within the pBR322 sequence, AlwNI and EcoRI. The AlwNI-BamHI and BamHI-EcoRI fragments flanking gene 3.5 were ligated with the appropriate AlwNI-EcoRI fragment from pBR322 to generate plasmid pAR4524, which joins T7 sequences AvaI-DraI (10,513-10,723) to AseI-BglII $(11,163-11,519)$ through the BamHI linker. The resulting deletion was transferred to phage DNA by growing wild-type T7 on a host carrying pAR4524, to allow homologous recombination between phage and plasmid. The fraction of deletion mutants in the progeny was increased by heat treatment, ${ }^{61}$ survivors were plated on a host that supplied a complementing amount of T7 lysozyme from a plasmid, and mutants were identified by inability to grow without the complementing plasmid. The presence of the $\Delta 3.5$ mutation was confirmed by restriction analysis.

Two different complementing plasmids were used for growing $\Delta 3.5$ mutant phage (Table 2). Plasmid pAR4503 contains an AvaII-AseI fragment of T7 DNA (10,665$11,164)$ cloned in the silent orientation in the BamHI site of pBR322 and should produce only small amounts of lysozyme. Plasmid pAR4521 contains the same fragment under control of the $\phi 2.5$, promoter, the natural promoter for gene 3.5 in T7 DNA (AluI fragment 9013-9380). Both plasmids supply enough lysozyme to support the growth of $\Delta 3.5$ but not so much that growth of wildtype T7 is inhibited (Table 2). The complementing plasmids have minimal homology with $\Delta 3.5$ phage, $60 \mathrm{bp}$ of T7 DNA to the left of the deletion and only the $10 \mathrm{bp}$ BamHI linker to the right, and no recombinant phages that recovered active lysozyme have been found in lysates of $\Delta 3.5$ propagated on hosts carrying either of these complementing plasmids. Plasmids that supply increasing levels of lysozyme become increasingly inhibitory to T7 growth (Table 2). In the

Table 4. Properties of T7 strains that carry different combinations of polymerase and lysozyme mutations. The mutations are described in Table 1

\begin{tabular}{|c|c|c|c|c|c|c|c|c|c|c|c|}
\hline \multicolumn{2}{|c|}{ Polymerase } & \multicolumn{3}{|c|}{ Lysozyme } & \multicolumn{7}{|c|}{ Properties of polymerase/lysozyme mutant combinations } \\
\hline Type & $\begin{array}{l}\text { Bind } \\
\text { lys }\end{array}$ & Type & $\begin{array}{c}\text { Bind } \\
\text { pol }\end{array}$ & $\begin{array}{l}\text { Amid- } \\
\text { ase }\end{array}$ & $\begin{array}{l}\text { lys/pol } \\
\text { complx }\end{array}$ & Plaques & $\begin{array}{c}\text { Shut-off T7 } \\
\text { RNA }\end{array}$ & $\begin{array}{l}\text { Repl } \\
\text { DNA }\end{array}$ & $\begin{array}{l}\text { Mature, } \\
\text { package }\end{array}$ & $\begin{array}{l}\text { Phage } \\
\text { yield }\end{array}$ & $\begin{array}{l}\text { Phage } \\
\text { release }\end{array}$ \\
\hline Wild & + & Wild & + & + & + & Large & + & +++ & +++ & +++ & +++ \\
\hline Wild & + & AK6 & 0 & + & 0 & Small & 0 & + & + & + & +++ \\
\hline Wild & + & AFK136 & + & 0 & + & 0 & + & +++ & +++ & +++ & 0 \\
\hline Wild & + & $\Delta 3.5$ & 0 & 0 & 0 & 0 & 0 & + & + & + & 0 \\
\hline $\mathrm{LH}$ & + & Wild & + & + & + & 0 & Premature & $\operatorname{Var}^{\mathbf{a}}$ & 0 & 0 & \\
\hline LH & + & AK6 & 0 & + & 0 & Large & 0 & +++ & +++ & +++ & +++ \\
\hline LH & + & $\Delta 3.5$ & 0 & 0 & 0 & 0 & 0 & +++ & +++ & +++ & 0 \\
\hline OL & + or 0 & Wild & + & + & + or 0 & ok & Delayed & +++ & +++ & +++ & +++ \\
\hline SLH & 0 & Wild & + & + & 0 & Small & & & & & \\
\hline $\mathrm{LH}, \mathrm{SLH}$ & 0 & Wild & + & + & 0 & Large & & & & & \\
\hline
\end{tabular}

a Wild-type lysozyme reduces replication of LH mutants to an extent that depends on the individual polymerase mutation. ${ }^{3}$ 
order of increasing lysozyme level, these include pAR4525, in which the lysozyme fragment of pAR4503 is under control of the $\phi 10$ promoter in pET-1, ${ }^{62}$ pAR4509, in which the same fragment is cloned in the orientation to be expressed from the tet promoter of pBR322, and pAR4532, in which the lysozyme fragment is both preceded and followed by a $\phi 10$ promoter.

The AK6 mutation deletes base-pairs 10,712-10,723 of T7 DNA, joining Ala1 of T7 lysozyme to Lys6 and removing amino acid residues $2-5$ (RVQF). ${ }^{17}$ To provide enough homologous DNA to transfer into T7, the AK6 mutation contained within the T7 sequence from the AvaI site at base-pair 10,512 to the HaeIII site at 11,296 was cloned in the AvaI-BamHI site of pBR322 to produce pAR4626. ${ }^{63} \Delta 3.5$ phage was grown on a host carrying pAR4626 (which provided $200 \mathrm{bp}$ of homologous sequence upstream of $\Delta 3.5$ and $135 \mathrm{bp}$ downstream) and phage that had acquired the AK6 deletion were selected for ability to grow on BL21. The presence of the AK6 mutation was confirmed by sequencing the phage DNA.

The AFK136 mutation deletes base-pairs 11,097-11,111 of T7 DNA, joining Ala129 of T7 lysozyme to Lys136 through a phenylalanine residue, removing amino acid residues 130-135 (CPSFDL). Plasmid pAR4591, which contains gene 3.5 and the $\phi 3.8$ promoter on an AvaIIHaeII fragment of T7 DNA ( base-pairs 10,665-11,296) under control of the $\phi 10$ promoter and $\mathrm{T} \phi$ terminator for T7 RNA polymerase in pET- $3,{ }^{62}$ was cut with AflII (T7 base-pair 11,111), digested to a limited extent with Bal31 nuclease, filled in with Klenow DNA polymerase, and religated. DNA sequencing showed that isolate 9-8 contained the deletion designated AFK136. As with $\Delta 3.5$, a phage containing the AFK136 deletion was obtained by genetic recombination with wild-type T7 and identified by inability to grow without a complementing plasmid. To avoid generating wild-type recombinants, the complementing plasmid for AFK136 was pTP298 (from A. Poteete), which supplied the R and Rz lysis proteins of $\lambda$ phage.

\section{Mutations in T7 RNA polymerase}

The amino acid changes of polymerase mutations determined by us are listed in Table 3. LH mutants previously isolated by random mutagenesis of a clone that expresses polymerase carry the designation $X$, and properties of X4 (A821T) and X19 (A465T) mutant phages have been reported. ${ }^{3}$ Other LH mutants, isolated as described in Results, carry designations BG and SNB (Tables 1 and 3). LR mutants include OL mutant polymerases, which allow the phages that contain them to form plaques on hosts that overproduce lysozyme from a plasmid in amounts sufficient to prevent wildtype T7 from forming plaques. ${ }^{15}$ The OL1-7 mutant phages were isolated earlier ${ }^{15}$ and the remainder here. OL1-7, 11-20 and 31-36 were isolated by plating wildtype T7 on HMS174/pAR1643 ${ }^{15}$ and OL21-30 and 41-46 were isolated on HMS174/pAR4593. ${ }^{17}$ SLH mutants, isolated as described in Results, are also LR mutants. The nucleotide change caused by each mutation was determined by DNA sequencing of phage DNA or a plasmid clone. In most cases, the mutation was located approximately by genetic combination with a set of phages with deletion end points at different places in the polymerase coding sequence. ${ }^{3}$ Mutations difficult to map genetically were identified entirely by sequencing.

\section{Crosses to obtain different combinations of polymerase and lysozyme mutations}

Crosses between T7 mutants were made by standard procedures, ${ }^{33}$ and the presence of desired deletions was confirmed by restriction analysis.

T7 mutant 4107 lacks the entire gene for T7 RNA polymerase and can grow only on a host that supplies active T7 RNA polymerase, such as BL21(DE2). ${ }^{56}$ The $4107, \Delta 3.5$ double mutant was obtained by co-infecting BL21 with 4107 and $\Delta 3.5$ and plating the resulting lysate on BL21(DE2)pAR4503, which supplies both wild-type polymerase and lysozyme. Individual plaques were spot tested on BL21, BL21(DE2), BL21/pAR4503, and BL21(DE2)pAR4503. The $4107, \Delta 3.5$ double mutant was identified as a plaque that could grow only on BL21(DE2)pAR4503. The 4107,AK6 double mutant was obtained by crossing $4107, \Delta 3.5$ with AK6, plating the lysate on BL21(DE2), and spot testing individual plaques on BL21 and BL21(DE2). The plaques that could not grow on BL21 were 4107,AK6.

The $X 4, \Delta 3.5$ double mutant was obtained by co-infecting $\mathrm{X} 4$ and $4107, \Delta 3.5$ on BL21/X4 in the presence of IPTG, which induces enough $X 4$ polymerase from the plasmid to allow growth. ${ }^{3}$ The $X 4, \Delta 3.5$ recombinants should be the only phages in the lysate able to form plaques on HMS174/pAR4626 (described above), which supplies AK6 mutant lysozyme. The presence of the $\Delta 3.5$ mutation was confirmed by the inability of this phage to grow on BL21 and by restriction analysis. The $X 19, \Delta 3.5$ double mutant was obtained in the same way, making the cross in BL21/X19 in the presence of IPTG. $B G, \Delta 3.5$ double mutants were obtained by crossing BG,AK6 mutants and $4107, \Delta 3.5$, plating the lysate on HMS174/pAR4626, and spot testing on BL21 and HMS174/pAR4626. Plaques that could not grow on BL21 were BG, $\Delta 3.5$. (The frequency of replacement of $\Delta 3.5$ by AK6 during growth of these double mutants was low enough not to be a problem, but complementing growth with a plasmid that furnishes the lysis genes of $\lambda$ would eliminate the possibility of such recombinants.)

\section{Expression and partial purification of mutant T7 RNA polymerases}

Mutant T7 RNA polymerases were obtained by expression from plasmids derived from pAR1219, which expresses wild-type polymerase from the lac UV5 promoter upon induction with IPTG. ${ }^{64}$ The $X$ mutants were isolated in this plasmid but mutations that were isolated in phages were transferred to the plasmid for expression of mutant polymerases. Mutations between amino acid residues 107 and 814 were transferred as an AlwNI-Acc65I fragment (3480-5618 of T7 DNA) to partially digested pAR1219 (which has two AlwNI sites). Mutations between amino acid residues 817 and the $\mathrm{C}$ terminus of the polymerase were obtained in Acc65I-EcoRI fragments by polymerase chain reaction (PCR) and restriction cutting, using a PCR primer to place an EcoRI site immediately following the termination codon for polymerase. These fragments replaced the Acc65I-EcoRI fragment of pAR1219 that contained the C-terminal portion of polymerase and base-pairs 1-375 of pBR322 DNA. The plasmid clones used for expressing mutant polymerases are listed in Table 3. 
To prepare T7 RNA polymerase, 100-ml cultures of BL21 carrying a cloned mutant polymerase were induced by IPTG at an $A_{600 \mathrm{~nm}}$ of 0.5 . After four hours of induction, the cells were collected, washed, and resuspended in $3 \mathrm{ml}$ of $50 \mathrm{mM}$ Tris $-\mathrm{HCl}$ (pH 8.0) $200 \mathrm{mM}$ $\mathrm{NaCl}, 2 \mathrm{mM}$ EDTA, and $1 \mathrm{mM}$ DTT. Egg-white lysozyme $(200 \mu \mathrm{g} / \mathrm{ml})$ was added together with $20 \mu \mathrm{g} / \mathrm{ml}$ of the proteinase inhibitor phenylmethylsulfonyl fluoride, and the mixture was kept on ice for 30 minutes. Half of the sample was lysed by four cycles of freezing and thawing, and the viscosity was reduced by sonication. The lysate was made $0.5 \%$ in polyethyleneimine and $0.2 \mathrm{M}$ $\mathrm{NH}_{4} \mathrm{SO}_{4}$ to precipitate nucleic acids. After 15 minutes on ice, the extract was centrifuged and the supernatant was diluted tenfold in buffer $\mathrm{A}$, which is $20 \mathrm{mM}$ sodium phosphate ( $\mathrm{pH}$ 7.7), $1 \mathrm{mM}$ EDTA, $5 \%$ (v/v) glycerol, and $1 \mathrm{mM}$ DTT. The diluted extract was loaded on to a mini-column containing $2 \mathrm{ml}$ of cellulose phosphate P11 (Whatman) equilibrated with buffer A. After washing with $8 \mathrm{ml}$ of buffer A containing $0.2 \mathrm{M} \mathrm{NaCl}$, the column was eluted with $0.4 \mathrm{M} \mathrm{NaCl}$ in buffer $\mathrm{A}$, and $0.5 \mathrm{ml}$ fractions were collected. Fractions 3 and 4 contained primarily T7 RNA polymerase. The enzyme concentration was determined by gel electrophoresis followed by Coomassie blue staining or Western blot using purified T7 RNA polymerase as standard. Typical yields were $1 \mathrm{mg}$ to $6 \mathrm{mg}$ from $50 \mathrm{ml}$ of induced culture.

\section{Transcription reactions}

Transcription reactions were carried out as described. ${ }^{16}$ Transcription buffer contained $40 \mathrm{mM}$ Tris$\mathrm{HCl}$ (pH 8.0), $4 \mathrm{mM} \mathrm{MgCl}_{2}, 4 \mathrm{mM}$ spermidine, $12 \mathrm{mM}$ $\beta$-mercaptoethanol, $100 \mu \mathrm{g} / \mathrm{ml}$ of bovine serum albumin. Reaction mixtures were preincubated at $37^{\circ} \mathrm{C}$ for three to five minutes and then nucleoside triphosphates $(0.4 \mathrm{mM}$ each) were added to initiate transcription. The duplex 48 -mer contains base-pairs -24 to +24 of the natural $\phi 10$ promoter. The lysozyme-mediated inhibition of transcription in the presence of $4 \mathrm{mM}$ spermidine, as used here, is expected to be not as severe as in its absence. ${ }^{16}$

\section{Utilization of cloned T7 origins of replication}

The following procedure is a modification of the method described by Rabkin \& Richardson. ${ }^{65}$ Cells were grown at $30{ }^{\circ} \mathrm{C}$ in $\mathrm{B} 25 \mathrm{P}$ medium to $A_{600 \mathrm{~nm}}$ of 0.4 , and infected with phage at a multiplicity of 3 . Aliquots of infected culture were labeled with $\left[{ }^{3} \mathrm{H}\right]$ thymidine at $40 \mu \mathrm{Ci} / \mathrm{ml}$. The labeling was stopped by adding 0.125 volume of lysis buffer ( $80 \mathrm{mM}$ Tris, $80 \mathrm{mM}$ EDTA and $4 \%$ SDS) and freezing in a dry-ice/ethanol bath. The samples were thawed and incubated with $125 \mu \mathrm{g} / \mathrm{ml}$ of proteinase $\mathrm{K}$ for two hours. The DNA was precipitated with isopropanol and suspended in $10 \mathrm{mM}$ Tris- $\mathrm{HCl}$ (pH 8.0), $0.1 \mathrm{mM} \mathrm{Na} \mathrm{NaDTA}_{3}$. DNA equivalent to about $50 \mu \mathrm{l}$ of original culture was digested with $\mathrm{XmnI}$ and analyzed by electrophoresis through an $0.8 \%(\mathrm{w} / \mathrm{v})$ agarose gel. The gel was fixed by soaking in $5 \%(\mathrm{v} / \mathrm{v})$ acetic acid and $5 \%(\mathrm{v} / \mathrm{v})$ isopropanol three times for ten minutes. After a thorough rinse in water, the gel was soaked in Autofluor ${ }^{\mathrm{TM}}$ (National Diagnostic) for three hours, dried, and exposed to Kodak X-0-mat film at $-70{ }^{\circ} \mathrm{C}$ with an intensifying screen.

Complete XmnI cleavage produces 13 fragments from mature T7 DNA plus the concatemer-junction and hairpin fragments, and two fragments from pBR322 DNA. The $\Delta 3.5$ deletion reduces the size of the second largest
XmnI fragment. The smaller fragment from pBR322 is well resolved (labeled P1 in Figure 4); the larger fragment (labeled P2) has a different size in different plasmids, because it carries the cloned fragment from T7 DNA.

\section{Acknowledgements}

We thank Rui Sousa for helpful discussions, and Rui Sousa \& John Dunn for permission to cite unpublished results. This work was supported by National Institutes of Health grant GM21872 and by the Office of Biological and Environmental Research of the United States Department of Energy.

\section{References}

1. Chamberlin, M., McGrath, J. \& Waskell, L. (1970). New RNA polymerase from Escherichia coli infected with bacteriophage T7. Nature, 228, 227-231.

2. Dunn, J. J. \& Studier, F. W. (1983). Complete nucleotide sequence of bacteriophage T7 DNA and the locations of T7 genetic elements. J. Mol. Biol. 166, 477-535.

3. Zhang, X. \& Studier, F. W. (1995). Isolation of transcriptionally active mutants of T7 RNA polymerase that do not support phage growth. J. Mol. Biol. 250, 156-168.

4. Rabkin, S. D. \& Richardson, C. C. (1988). Initiation of DNA replication at cloned origins of bacteriophage T7. J. Mol. Biol. 204, 903-916.

5. Romano, L. J., Tamanoi, F. \& Richardson, C. C. (1981). Initiation of DNA replication at the primary origin of bacteriophage T7 by purified proteins: requirement for T7 RNA polymerase. Proc. Natl Acad. Sci. USA, 78, 4107-4111.

6. Sugimoto, K., Kohara, Y. \& Okazaki, T. (1987). Relative roles of T7 RNA polymerase and gene 4 primase for the initiation of T7 phage DNA replication in vivo. Proc. Natl Acad. Sci. USA, 84, 3977-3981.

7. Kelly, T. J., Jr \& Thomas, C. A., Jr (1969). An intermediate in the replication of bacteriophage T7 DNA molecules. J. Mol. Biol. 44, 459-475.

8. Chung, Y. B. \& Hinkle, D. C. (1990). Bacteriophage T7 DNA packaging. II. Analysis of the DNA sequences required for packaging using a plasmid transduction assay. J. Mol. Biol. 216, 927-938.

9. Hashimoto, C. \& Fujisawa, H. (1992). Transcription dependence of DNA packaging of bacteriophages T3 and T7. Virology, 191, 246-250.

10. Herrlich, P., Schweiger, M. \& Sauerbier, W. (1971). Host- and phage-RNA polymerase mediated synthesis of T 7 lysozyme in vivo. Mol. Gen. Genet. 112, $152-160$.

11. Inouye, M., Arnheim, N. \& Sternglanz, R. (1973). Bacteriophage T7 lysozyme is an N-acetylmuramylL-alanine amidase. J. Biol. Chem. 248, 7247-7252.

12. Studier, F. W. (1972). Bacteriophage T7. Science, 176, 367-376.

13. Silberstein, S., Inouye, M. \& Studier, F. W. (1975). Studies on the role of bacteriophage T7 lysozyme during phage infection. J. Mol. Biol. 96, 1-11.

14. McAllister, W. T. \& Wu, H. L. (1978). Regulation of 
transcription of the late genes of bacteriophage T7. Proc. Natl Acad. Sci. USA, 75, 804-808.

15. Moffatt, B. A. \& Studier, F. W. (1987). T7 lysozyme inhibits transcription by T7 RNA polymerase. Cell, $49,221-227$.

16. Zhang, X. \& Studier, F. W. (1997). Mechanism of inhibition of bacteriophage T7 RNA polymerase by T7 lysozyme. J. Mol. Biol. 269, 10-27.

17. Cheng, X., Zhang, X., Pflugrath, J. W. \& Studier, F. W. (1994). The structure of bacteriophage T7 lysozyme, a zinc amidase and an inhibitor of T7 RNA polymerase. Proc. Natl Acad. Sci. USA, 91, 4034-4038.

18. Jeruzalmi, D. \& Steitz, T. A. (1998). Structure of T7 RNA polymerase complexed to the transcriptional inhibitor T7 lysozyme. EMBO J. 17, 4101-4113.

19. Sousa, R., Chung, Y. J., Rose, J. P. \& Wang, B. C. (1993). Crystal structure of bacteriophage T7 RNA polymerase at $3.3 \AA$ resolution. Nature, 364, 593-599.

20. Cheetham, G. M., Jeruzalmi, D. \& Steitz, T. A. (1999). Structural basis for initiation of transcription from an RNA polymerase-promoter complex. Nature, 399, $80-83$.

21. Cheetham, G. M. \& Steitz, T. A. (1999). Structure of a transcribing T7 RNA polymerase initiation complex. Science, 286, 2305-2309.

22. Yin, Y. W. \& Steitz, T. A. (2002). Structural basis for the transition from initiation to elongation transcription in T7 RNA polymerase. Science, 298, 1387-1395.

23. Tahirov, T. H., Temiakov, D., Anikin, M., Patlan, V., McAllister, W. T., Vassylyev, D. G. \& Yokoyama, S. (2002). Structure of a T7 RNA polymerase elongation complex at $2.9 \AA$ resolution. Nature, 420, 43-50.

24. Young, R. (1992). Bacteriophage lysis: mechanism and regulation. Microbiol. Rev. 56, 430-481.

25. Chung, Y. B., Nardone, C. \& Hinkle, D. C. (1990). Bacteriophage T7 DNA packaging. III. A "hairpin" end formed on T7 concatemers may be an intermediate in the processing reaction. J. Mol. Biol. 216, 939-948.

26. Tamanoi, F., Saito, H. \& Richardson, C. C. (1980). Physical mapping of primary and secondary origins of bacteriophage T7 DNA replication. Proc. Natl Acad. Sci. USA, 77, 2656-2660.

27. Huang, J., Villemain, J., Padilla, R. \& Sousa, R. (1999). Mechanisms by which T7 lysozyme specifically regulates T7 RNA polymerase during different phases of transcription. J. Mol. Biol. 293, 457-475.

28. Kumar, A. \& Patel, S. S. (1997). Inhibition of T7 RNA polymerase: transcription initiation and transition from initiation to elongation are inhibited by T7 lysozyme via a ternary complex with RNA polymerase and promoter DNA. Biochemistry, 36, 13954-13962.

29. Villemain, J. \& Sousa, R. (1998). Specificity in transcriptional regulation in the absence of specific DNA binding sites: the case of T7 lysozyme. J. Mol. Biol. 281, 793-802.

30. Stano, N. M. \& Patel, S. S. (2004). T7 lysozyme represses T7 RNA polymerase transcription by destabilizing the open complex during initiation. J. Biol. Chem. 279, 16136-16143.

31. Lyakhov, D. L., He, B., Zhang, X., Studier, F. W., Dunn, J. J. \& McAllister, W. T. (1997). Mutant bacteriophage T7 RNA polymerases with altered termination properties. J. Mol. Biol. 269, 28-40.

32. Lyakhov, D. L., He, B., Zhang, X., Studier, F. W., Dunn, J. J. \& McAllister, W. T. (1998). Pausing and termination by bacteriophage T7 RNA polymerase. J. Mol. Biol. 280, 201-213.
33. Studier, F. W. (1969). The genetics and physiology of bacteriophage T7. Virology, 39, 562-574.

34. Wang, I. N., Smith, D. L. \& Young, R. (2000). Holins: the protein clocks of bacteriophage infections. Annu. Rev. Microbiol. 54, 799-825.

35. Stone, J. C., Smith, R. D. \& Miller, R. C., Jr (1983). A recombinant DNA plasmid which inhibits bacteriophage T7 reproduction in Escherichia coli. J. Gen. Virol. 64, 1615-1622.

36. Kim, J. S., Kim, S. H. \& Chung, Y. B. (1997). Defects in concatemer processing of bacteriophage T7 DNA deleted in the M-hairpin region. Virology, 236, 37-46.

37. Fuller, C. W. \& Richardson, C. C. (1985). Initiation of DNA replication at the primary origin of bacteriophage T7 by purified proteins. Site and direction of initial DNA synthesis. J. Biol. Chem. 260, 3185-3196.

38. Chung, Y. B. \& Hinkle, D. C. (1990). Bacteriophage T7 DNA packaging. I. Plasmids containing a T7 replication origin and the T7 concatemer junction are packaged into transducing particles during phage infection. J. Mol. Biol. 216, 911-926.

39. Studier, F. W. \& Hausmann, R. (1969). Integration of two sets of T7 mutants. Virology, 39, 587-588.

40. Roeder, G. S. \& Sadowski, P. D. (1977). Bacteriophage T7 morphogenesis: phage-related particles in cells infected with wild-type and mutant T7 phage. Virology, 76, 263-285.

41. Hartvig, L. \& Christiansen, J. (1996). Intrinsic termination of T7 RNA polymerase mediated by either RNA or DNA. EMBO J. 15, 4767-4774

42. He, B., Kukarin, A., Temiakov, D., Chin-Bow, S. T., Lyakhov, D. L., Rong, M. et al. (1998). Characterization of an unusual, sequence-specific termination signal for T7 RNA polymerase. J. Biol. Chem. 273, 18802-18811.

43. Kwon, Y. S. \& Kang, C. (1999). Bipartite modular structure of intrinsic, RNA hairpin-independent termination signal for phage RNA polymerases. J. Biol. Chem. 274, 29149-29155.

44. Song, H. \& Kang, C. (2001). Sequence-specific termination by T7 RNA polymerase requires formation of paused conformation prior to the point of RNA release. Genes Cells, 6, 291-301.

45. Brieba, L. G., Gopal, V. \& Sousa, R. (2001). Scanning mutagenesis reveals roles for helix $\mathrm{n}$ of the bacteriophage T7 RNA polymerase thumb subdomain in transcription complex stability, pausing, and termination. J. Biol. Chem. 276, 10306-10313.

46. Pajunen, M. I., Elizondo, M. R., Skurnik, M., Kieleczawa, J. \& Molineux, I. J. (2002). Complete nucleotide sequence and likely recombinatorial origin of bacteriophage T3. J. Mol. Biol. 319, $1115-1132$.

47. Garcia, E., Elliott, J. M., Ramanculov, E., Chain, P. S., Chu, M. C. \& Molineux, I. J. (2003). The genome sequence of Yersinia pestis bacteriophage phiA1122 reveals an intimate history with the coliphage T3 and T7 genomes. J. Bacteriol. 185, 5248-5262.

48. Pajunen, M. I., Kiljunen, S. J., Soderholm, M. E. \& Skurnik, M. (2001). Complete genomic sequence of the lytic bacteriophage phiYeO3-12 of Yersinia enterocolitica serotype O:3. J. Bacteriol. 183, 1928-1937.

49. Dietz, A., Weisser, H. J., Kossel, H. \& Hausmann, R. (1990). The gene for Klebsiella bacteriophage K11 RNA polymerase: sequence and comparison with the homologous genes of phages T7, T3, and SP6. Mol. Gen. Genet. 221, 283-286.

50. Kovalyova, I. V. \& Kropinski, A. M. (2003). The complete genomic sequence of lytic bacteriophage gh-1 
infecting Pseudomonas putida-evidence for close relationship to the T7 group. Virology, 311, 305-315.

51. Mookhtiar, K. A., Peluso, P. S., Muller, D. K., Dunn, J. J. \& Coleman, J. E. (1991). Processivity of T7 RNA polymerase requires the C-terminal Phe882-Ala883COO- or "foot". Biochemistry, 30, 6305-6313.

52. Patra, D., Lafer, E. M. \& Sousa, R. (1992). Isolation and characterization of mutant bacteriophage T7 RNA polymerases. J. Mol. Biol. 224, 307-318.

53. Gardner, L. P., Mookhtiar, K. A. \& Coleman, J. E. (1997). Initiation, elongation, and processivity of carboxyl-terminal mutants of T7 RNA polymerase. Biochemistry, 36, 2908-2918.

54. Brieba, L. G. \& Sousa, R. (2001). The T7 RNA polymerase intercalating hairpin is important for promoter opening during initiation but not for RNA displacement or transcription bubble stability during elongation. Biochemistry, 40, 3882-3890.

55. Stano, N. M., Levin, M. K. \& Patel, S. S. (2002). The +2 NTP binding drives open complex formation in T7 RNA polymerase. J. Biol. Chem. 277, 37292-37300.

56. Studier, F. W. \& Moffatt, B. A. (1986). Use of bacteriophage T7 RNA polymerase to direct selective highlevel expression of cloned genes. J. Mol. Biol. 189, $113-130$.

57. Studier, F. W. (1975). Genetic mapping of a mutation that causes ribonuclease III deficiency in Escherichia coli. J. Bacteriol. 124, 307-316.
58. Moffatt, B. A., Dunn, J. J. \& Studier, F. W. (1984). Nucleotide sequence of the gene for bacteriophage T7 RNA polymerase. J. Mol. Biol. 173, 265-269.

59. Sutcliffe, J. G. (1979). Complete nucleotide sequence of the Escherichia coli plasmid pBR322. Cold Spring Harb. Symp. Quant. Biol. 43, 77-90.

60. Studier, F. W. \& Rosenberg, A. H. (1981). Genetic and physical mapping of the late region of bacteriophage T7 DNA by use of cloned fragments of T7 DNA. J. Mol. Biol. 153, 503-525.

61. Studier, F. W. (1973). Genetic analysis of non-essential bacteriophage T7 genes. J. Mol. Biol. 79, 227-236.

62. Rosenberg, A. H., Lade, B. N., Chui, D. S., Lin, S. W., Dunn, J. J. \& Studier, F. W. (1987). Vectors for selective expression of cloned DNAs by T7 RNA polymerase. Gene, 56, 125-135.

63. Zhang, X. (1995). T7 RNA polymerase and T7 lysozyme: genetic, biochemical, and structural analysis of their interaction and multiple roles in T7 infection, State University of New York at Stony Brook.

64. Davanloo, P., Rosenberg, A. H., Dunn, J. J. \& Studier, F. W. (1984). Cloning and expression of the gene for bacteriophage T7 RNA polymerase. Proc. Natl Acad. Sci. USA, 81, 2035-2039.

65. Rabkin, S. D. \& Richardson, C. C. (1990). In vivo analysis of the initiation of bacteriophage T7 DNA replication. Virology, 174, 585-592.

Edited by M. Gottesman 